\title{
Pure hydrocarbon cycles in TMC-1: Discovery of ethynyl cyclopropenylidene, cyclopentadiene, and indene ${ }^{\star}$
}

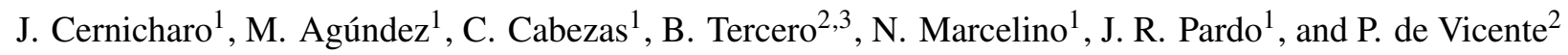 \\ ${ }^{1}$ Grupo de Astrofísica Molecular, Instituto de Física Fundamental (IFF-CSIC), C/ Serrano 121, 28006 Madrid, Spain \\ e-mail: jose.cernicharo@csic.es \\ ${ }^{2}$ Centro de Desarrollos Tecnológicos, Observatorio de Yebes (IGN), 19141 Yebes, Guadalajara, Spain \\ 3 Observatorio Astronómico Nacional (OAN, IGN), Madrid, Spain
}

Received 22 April 2021 / Accepted 28 April 2021

\begin{abstract}
We report the detection for the first time in space of three new pure hydrocarbon cycles in TMC-1: $c-\mathrm{C}_{3} \mathrm{HCCH}$ (ethynyl cyclopropenylidene), $c-\mathrm{C}_{5} \mathrm{H}_{6}$ (cyclopentadiene), and $c-\mathrm{C}_{9} \mathrm{H}_{8}$ (indene). We derive a column density of $3.1 \times 10^{11} \mathrm{~cm}^{-2}$ for the first cycle and similar values, in the range $(1-2) \times 10^{13} \mathrm{~cm}^{-2}$, for the second and third. This means that cyclopentadiene and indene, in spite of their large size, are exceptionally abundant, only a factor of five less abundant than the ubiquitous cyclic hydrocarbon $c-\mathrm{C}_{3} \mathrm{H}_{2}$. The high abundance found for these two hydrocarbon cycles together with the high abundance previously found for the propargyl radical $\left(\mathrm{CH}_{2} \mathrm{CCH}\right)$ and other hydrocarbons, such as vinyl and allenyl acetylene (Agúndez et al. 2021, A\&A, 647, L10; Cernicharo et al. 2021a, A\&A, 647, L2; Cernicharo et al. 2021b, A\&A, 647, L3), start to allow us to quantify the abundant content of hydrocarbon rings in cold dark clouds and to identify the intermediate species that are probably behind the in situ bottom-up synthesis of aromatic cycles in these environments. While $c-\mathrm{C}_{3} \mathrm{HCCH}$ is most likely formed through the reaction between the radical $\mathrm{CCH}$ and $c-\mathrm{C}_{3} \mathrm{H}_{2}$, the high observed abundances of cyclopentadiene and indene are difficult to explain through currently proposed chemical mechanisms. Further studies are needed to identify how five- and six-membered rings are formed under the cold conditions of a cloud such as TMC-1.
\end{abstract}

Key words. molecular data - line: identification - ISM: molecules - ISM: individual objects: TMC-1 - astrochemistry

\section{Introduction}

Since polycyclic aromatic hydrocarbons (PAHs) were first hypothesized to be carriers of the unidentified infrared bands (Léger \& Puget 1984; Allamandola et al. 1985), a great deal of effort has been devoted to understanding the chemical processes leading to the formation of these molecular species (see e.g. Joblin \& Cernicharo 2018). Circumstellar envelopes around carbon-rich asymptotic giant branch (AGB) stars have been suggested as the factories of PAHs (Cherchneff et al. 1992). The detection of benzene in the carbon-rich protoplanetary nebula CRL 618 (Cernicharo et al. 2001) suggests a bottom-up approach in which the small hydrocarbons that formed during the AGB phase, such as $\mathrm{C}_{2} \mathrm{H}_{2}$ and $\mathrm{C}_{2} \mathrm{H}_{4}$, interact with the ultraviolet (UV) radiation produced by the star in its evolution to the white dwarf phase (Woods et al. 2002; Cernicharo 2004). Other hypotheses involve the processing of dust grains around evolved stars, either through UV photons (Pilleri et al. 2015) or by chemical processes (Martínez et al. 2020). Hence, it has been surprising to see that cyanide derivatives of PAHs have been found in the cold pre-stellar core TMC-1, which is well

\footnotetext{
* Based on observations carried out with the Yebes $40 \mathrm{~m}$ telescope (projects 19A003, 20A014, 20D023, and 21A011) and the Institut de Radioastronomie Millimétrique (IRAM) $30 \mathrm{~m}$ telescope. The $40 \mathrm{~m}$ radio telescope at Yebes Observatory is operated by the Spanish Geographic Institute (IGN; Ministerio de Transportes, Movilidad y Agenda Urbana). IRAM is supported by INSU/CNRS (France), MPG (Germany), and IGN (Spain).
}

protected against UV radiation (McGuire et al. 2018, 2021). It is unlikely that these PAH cyanides arise from a reservoir of PAHs that has existed since the early stages of the cloud since these relatively small PAHs would not have survived the diffuse cloud stage. Although McGuire et al. (2021) propose a reasonable chemical network starting with the phenyl radical that could explain the observed abundances of cyanonaphthalene, the chemical routes leading to benzene itself are still unclear. An in situ formation mechanism for benzene must involve abundant hydrocarbons containing from two to four carbon atoms. Moreover, some of these species have to permit an easy cyclization in two to three steps to have an efficient yield of benzene or phenyl radical. The propargyl radical $\left(\mathrm{CH}_{2} \mathrm{CCH}\right)$ was recently found in TMC-1 by Agúndez et al. (2021) with an abundance close to $10^{-8}$ relative to $\mathrm{H}_{2}$. In addition, complex hydrocarbons such as vinyl and allenyl acetylene have also been observed in very large abundances (Cernicharo et al. 2021a,b). These hydrocarbons may hold the key to the formation of initial aromatic rings, from which larger PAHs can grow.

In this Letter we report the discovery of three pure hydrocarbon cycles (see Fig. 1): $c-\mathrm{C}_{3} \mathrm{HCCH}$ (ethynyl cyclopropenylidene), $c-\mathrm{C}_{5} \mathrm{H}_{6}$ (cyclopentadiene), and $c-\mathrm{C}_{9} \mathrm{H}_{8}$ (indene) ${ }^{1}$.

\footnotetext{
1 We learned in a virtual seminar during the final phase of preparation of this work that a paper claiming the detection of this species in TMC-1 has been submitted (Burkhardt et al. 2021). We know neither its contents nor the quality of the detection.
} 


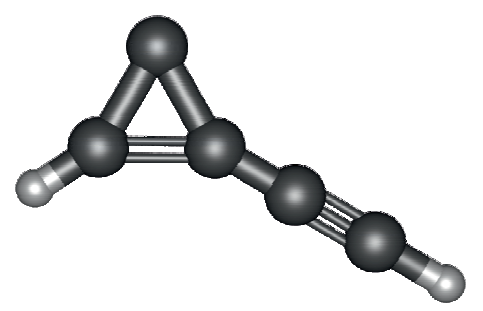

Ethynyl cyclopropenylidene, $\mathrm{c}-\mathrm{C}_{3} \mathrm{HCCH}$
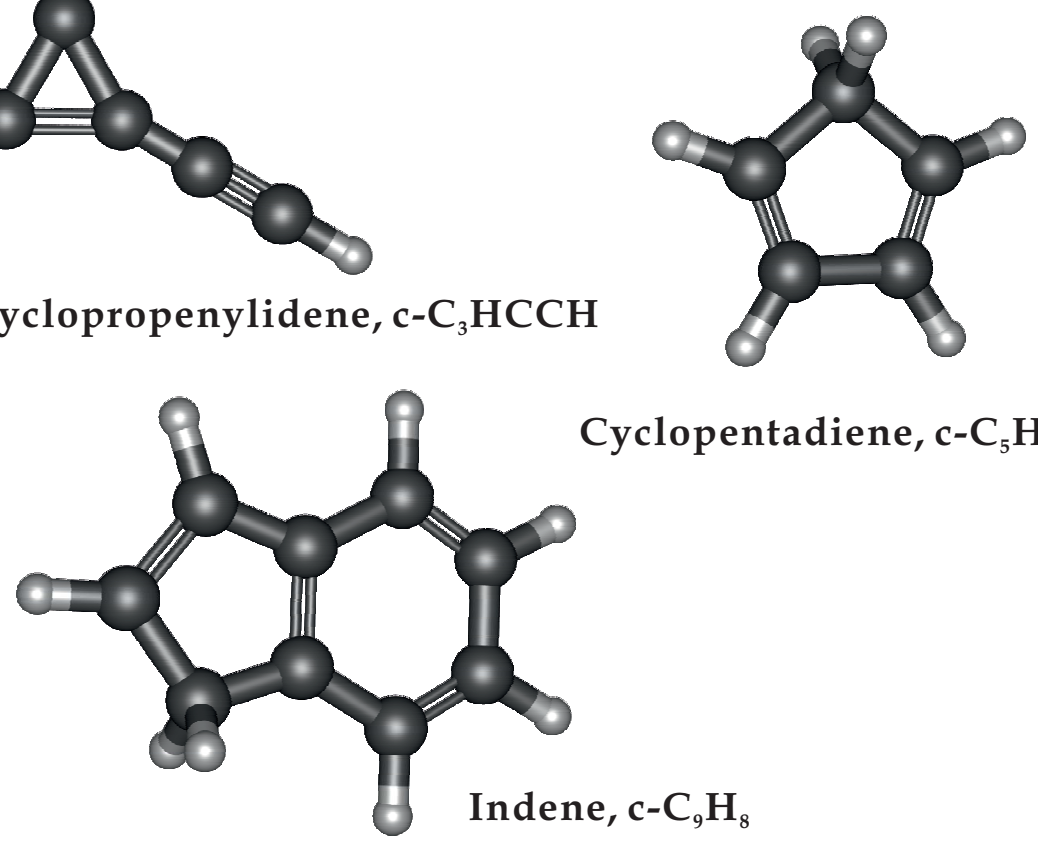

Fig. 1. Structures of the three species detected in this work.

\section{Observations}

New receivers, built within the Nanocosmos project ${ }^{2}$ and installed at the Yebes $40 \mathrm{~m}$ radio telescope, were used for the observations of TMC-1. The $Q$-band receiver consists of two high electron mobility transistor cold amplifiers that cover the $31.0-50.3 \mathrm{GHz}$ band with horizontal and vertical polarizations. Receiver temperatures vary from $22 \mathrm{~K}$ at $32 \mathrm{GHz}$ to $42 \mathrm{~K}$ at $50 \mathrm{GHz}$. The back ends are $2 \times 8 \times 2.5 \mathrm{GHz}$ fast Fourier transform spectrometers with a spectral resolution of $38.15 \mathrm{kHz}$ that provide the whole coverage of the $Q$-band in both polarizations. The main beam efficiency varies from 0.6 at $32 \mathrm{GHz}$ to 0.43 at $50 \mathrm{GHz}$. A detailed description of the system is given by Tercero et al. (2021).

The line survey of TMC- $1\left(\alpha_{\mathrm{J} 2000}=4^{\mathrm{h}} 41^{\mathrm{m}} 41.9^{\mathrm{s}}\right.$ and $\delta_{\mathrm{J} 2000}=$ $\left.+25^{\circ} 41^{\prime} 27.0^{\prime \prime}\right)$ in the $Q$-band was performed in several sessions. Previous results on the detection of $\mathrm{C}_{3} \mathrm{~N}^{-}$and $\mathrm{C}_{5} \mathrm{~N}^{-}$ (Cernicharo et al. 2020a), $\mathrm{HC}_{5} \mathrm{NH}^{+}$(Marcelino et al. 2020), $\mathrm{HC}_{4} \mathrm{NC}$ (Cernicharo et al. 2020b), and $\mathrm{HC}_{3} \mathrm{O}^{+}$(Cernicharo et al. 2020c) were based on two observing runs, performed in November 2019 and February 2020. Two different frequency coverages were used, $31.08-49.52 \mathrm{GHz}$ and $31.98-50.42 \mathrm{GHz}$, in order to ensure that no spurious spectral ghosts were produced in the down-conversion chain. Additional data were taken in October 2020, December 2020, and January-April 2021. The observing procedure was frequency switching with a frequency throw of $10 \mathrm{MHz}$ for the first two runs and of $8 \mathrm{MHz}$ for all the others.

All data were analysed using the GILDAS package ${ }^{3}$.

\section{Results}

The sensitivity of our TMC-1 data is better than that of previously published line surveys of this source at the same frequencies (Kaifu et al. 2004) by a factor of 10-20. In fact, it has been possible to detect many individual lines from molecules that were reported previously using only stacking techniques (Marcelino et al. 2021). The recent discovery of some molecules

\footnotetext{
2 https://nanocosmos.iff.csic.es/

3 http://wWw. iram. fr/IRAMFR/GILDAS
}

containing the ethynyl group $(\mathrm{CCH})$, such as vinyl and allenyl acetylene (Cernicharo et al. 2021a,b), and of the propargyl radical (Agúndez et al. 2021) prompted us to search for other chemically related hydrocarbons. Line identification in this work was done using the catalogues MADEX (Cernicharo 2012), CDMS (Müller et al. 2005), and JPL (Pickett et al. 1998).

\subsection{Ethynyl cyclopropenylidene $\left(\mathrm{c}-\mathrm{C}_{3} \mathrm{HCCH}\right)$}

Cyclopropenylidene $\left(c-\mathrm{C}_{3} \mathrm{H}_{2}\right)$ is an abundant species in cold dark clouds. Several lines of the para species of this molecule were detected in our line survey. They are analysed in Appendix D. The reaction of this molecule with $\mathrm{CCH}$ and $\mathrm{CN}$ could lead to the formation of $c-\mathrm{C}_{3} \mathrm{HCCH}$ and $\mathrm{c}-\mathrm{C}_{3} \mathrm{HCN}$. Ethynyl cyclopropenylidene $\left(c-\mathrm{C}_{3} \mathrm{HCCH}\right.$; see Fig. 1) is one of the various $\mathrm{C}_{5} \mathrm{H}_{2}$ isomers (see Appendix $\mathrm{B}$ ) that have been studied by microwave spectroscopy in the laboratory (Travers et al. 1997; McCarthy et al. 1997; Gottlieb et al. 1998). Other such isomers are $l-\mathrm{H}_{2} \mathrm{C}_{5}$, the bent $\mathrm{HCC}(\mathrm{CH}) \mathrm{CC}$, and the cycle $c-\mathrm{H}_{2} \mathrm{C}_{3} \mathrm{CC}$. All these species are implemented in the MADEX code (Cernicharo 2012). In the case of $c-\mathrm{C}_{3} \mathrm{HCCH}$, the dipole moment components are $\mu_{a}=2.04 \mathrm{D}$ and $\mu_{b}=2.89 \mathrm{D}$ (Travers et al. 1997).

A search for $c-\mathrm{C}_{3} \mathrm{HCCH}$ resulted in the detection of 13 rotational lines, which gives a high degree of confidence in the detection of this species. Nevertheless, the lines are weak, with intensities around $1 \mathrm{mK}$. Some of them are shown in Fig. 2. The derived line parameters (see Appendix A) are given in Table A.1. A few lines that could have been detected in our survey appear blended with lines from other species or are affected by negative features produced in the folding of the frequency switching procedure. These cases are indicated in Table A.1. An analysis of the observed intensities through a rotational diagram provides a rotational temperature of $8 \pm 3 \mathrm{~K}$ and a column density for $c-\mathrm{C}_{3} \mathrm{HCCH}$ of $(3.1 \pm 0.8) \times 10^{11} \mathrm{~cm}^{-2}$. We assumed a line width of $1.0 \mathrm{~km} \mathrm{~s}^{-1}$, which corresponds to the observed average value, and a source of uniform brightness temperature with a diameter of $80^{\prime \prime}$ (Fossé et al. 2001). We performed a model fitting directly to the observed line profiles as described by Cernicharo et al. (2021c), with the result that the best match 

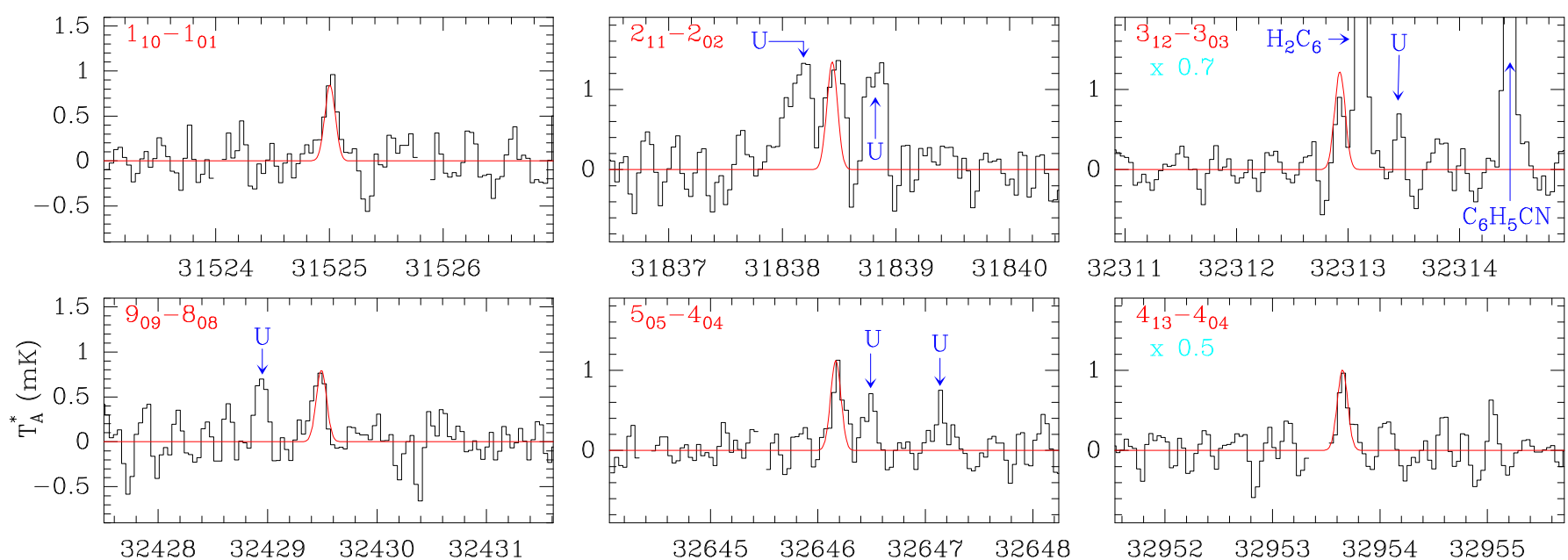

$32311 \quad 32312 \quad 32313 \quad 32314$
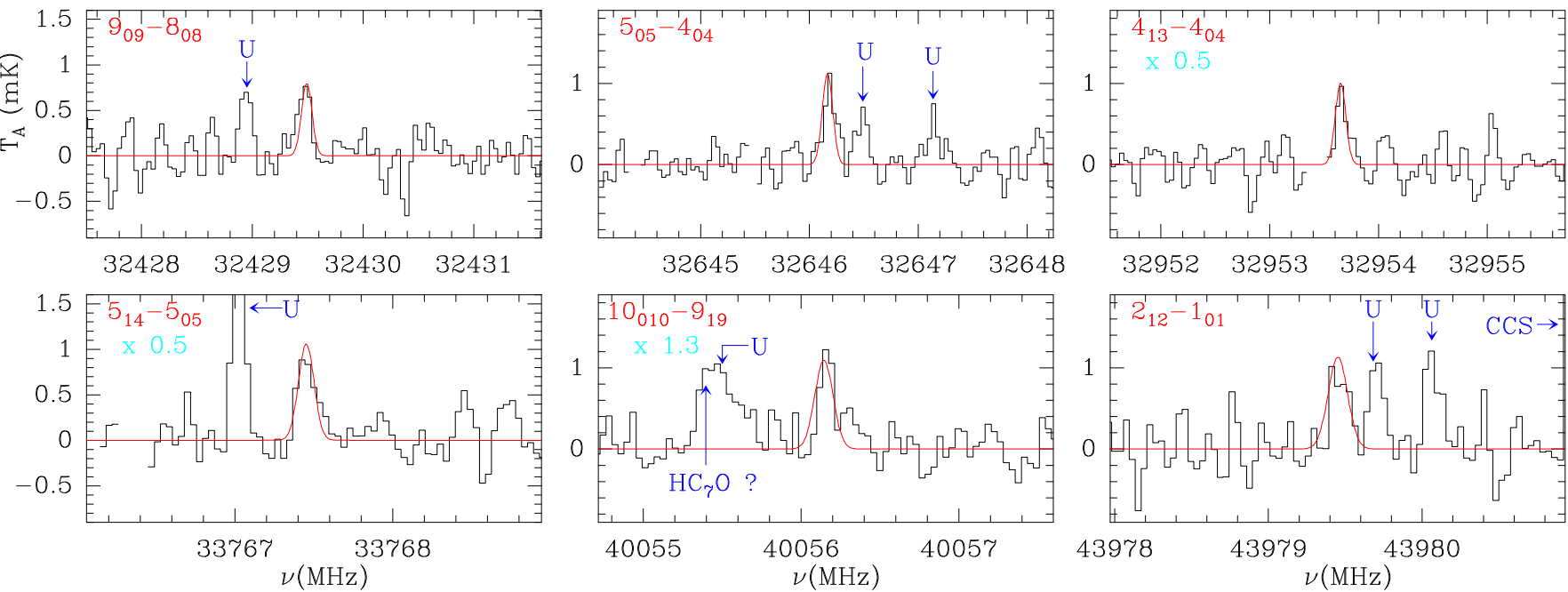

Fig. 2. Selected transitions of $c-\mathrm{C}_{3} \mathrm{HCCH}$ in TMC-1. The abscissa corresponds to the rest frequency of the lines, assuming a local standard of rest velocity of the source of $5.83 \mathrm{~km} \mathrm{~s}^{-1}$. Frequencies and intensities for the observed lines are given in Table A.1. The ordinate is the antenna temperature, corrected for atmospheric and telescope losses, in millikelvins. The quantum numbers for each transition are indicated in the upper left corner of the corresponding panel. The red lines show the computed synthetic spectrum for this species for $T_{\mathrm{r}}=10 \mathrm{~K}$ and a column density of $3.1 \times 10^{11} \mathrm{~cm}^{-2}$. Cyan labels indicate the multiplicative factor applied to the model to match the intensity of the observed lines.

between the computed synthetic spectrum and the observations corresponds to $T_{\mathrm{r}}=10 \mathrm{~K}$ and a column density similar to that derived from the rotation diagram. Figure 2 shows, in red, the computed synthetic spectrum. The correction factors applied to each line to match the observations are indicated in the figure. Taking the signal-to-noise ratio of the data into account, these factors are within the expected uncertainties of the fit.

Adopting a column density of $\mathrm{H}_{2}$ of $10^{22} \mathrm{~cm}^{-2}$ for TMC1 (Cernicharo \& Guélin 1987), the abundance of $c-\mathrm{C}_{3} \mathrm{HCCH}$ relative to $\mathrm{H}_{2}$ is $3.1 \times 10^{-11}$, which is significantly below those of $c-\mathrm{C}_{3} \mathrm{H}_{2}$ and $c-\mathrm{C}_{3} \mathrm{H}\left(5.9 \times 10^{-9}\right.$ and $6.2 \times 10^{-10}$, respectively; see Appendices D and E), ethynyl derivatives such as vinyl, methyl, and allenyl acetylene (Cernicharo et al. 2021a,b; Cabezas et al. 2021), and propylene (Marcelino et al. 2007). We derive the following abundance ratios: $c-\mathrm{C}_{3} \mathrm{H}_{2} / c-\mathrm{C}_{3} \mathrm{HCCH} \sim 190$ (see Appendix D), $c-\mathrm{C}_{3} \mathrm{H} / c-\mathrm{C}_{3} \mathrm{HCCH} \sim 20$, and $c-\mathrm{C}_{3} \mathrm{H}_{2} / c$ $\mathrm{C}_{3} \mathrm{H} \sim 10$. Upper limits to the column densities of the isomers of $c-\mathrm{C}_{3} \mathrm{HCCH}$ are analysed in Appendix B. Improved rotational and distortion constants for $c-\mathrm{C}_{3} \mathrm{HCCH}$ are given in Appendix $\mathrm{C}$.

\subsection{Cyclopentadiene $\left(c-C_{5} H_{6}\right)$}

The recent detection via stacking techniques of two cyanide derivatives of cyclopentadiene in TMC-1 (Lee et al. 2021) makes it very likely that cyclopentadiene itself is also present in this source. Cyclopentadiene (see Fig. 1) has been observed in the laboratory up to $386.6 \mathrm{GHz}$ by different authors (Laurie 1956; Scharpen \& Laurie 1965; Benson \& Flygare 1970; Bogey et al. 1988). The molecule has a low dipole moment of $0.416 \mathrm{D}$ along its $b$ axis (Laurie 1956). Because of the $\mathrm{C}_{2 v}$ symmetry of the molecule, two spin species - ortho and para, with $K_{a}+K_{c}$ odd and even and statistical weights 9 and 7 , respectively - have to be considered. The lowest ortho level is the $1_{1,1}$, and it is $0.6 \mathrm{~K}$ above the lowest para level $\left(0_{0,0}\right)$. We searched for this species in our TMC-1 data, and we detected all the strong lines in the $31-50 \mathrm{GHz}$ frequency range. They are shown in Fig. 3, and the line parameters are given in Table A.1. Only one para line, the $4_{1,3}-3_{2,2}$, which is affected by a negative frequency-switching artefact, is missing. Another para line, the $4_{0,4}-3_{1,3}$, is strongly blended with a line from $c-\mathrm{C}_{3} \mathrm{HD}$ (see the third panel from the top in Fig. 3). Taking the large geometrical section of the molecule and the low dipole moment into account, we could expect to have its rotational levels thermalized at the kinetic temperature of the cloud, $10 \mathrm{~K}$. Assuming the same source parameters as for $c-\mathrm{C}_{3} \mathrm{HCCH}$, we derive a total column density for cyclopentadiene of $(1.2 \pm 0.3) \times 10^{13} \mathrm{~cm}^{-2}$, with identical contributions from the ortho and para species. The fractional abundance of $c-\mathrm{C}_{5} \mathrm{H}_{6}$ relative to $\mathrm{H}_{2}$ is thus $1.2 \times 10^{-9}$. This abundance is identical to that of $\mathrm{CH}_{2} \mathrm{CHCCH}$ (Cernicharo et al. 2021b) and $\mathrm{H}_{2} \mathrm{CCHCCH}$ (Cernicharo et al. 2021c), and lower than that of the propargyl radical by a factor of $\sim 7$ (Agúndez et al. 2021). Cyclopentadiene is respectively 15 and 63 times more abundant than 1- and 2-cyanocyclopentadiene, its cyano derivatives (Lee et al. 2021).

\subsection{Indene $\left(\mathrm{c}-\mathrm{C}_{9} \mathrm{H}_{8}\right)$}

Indene $\left(c-\mathrm{C}_{9} \mathrm{H}_{8}\right)$ has a bicyclic structure with a six-membered ring fused to a five-membered ring (see Fig. 1). It has been studied in the microwave laboratory by Li et al. (1979) and Caminati (1993). The accuracy of these measurements is moderate, with typical uncertainties for the measured frequencies 

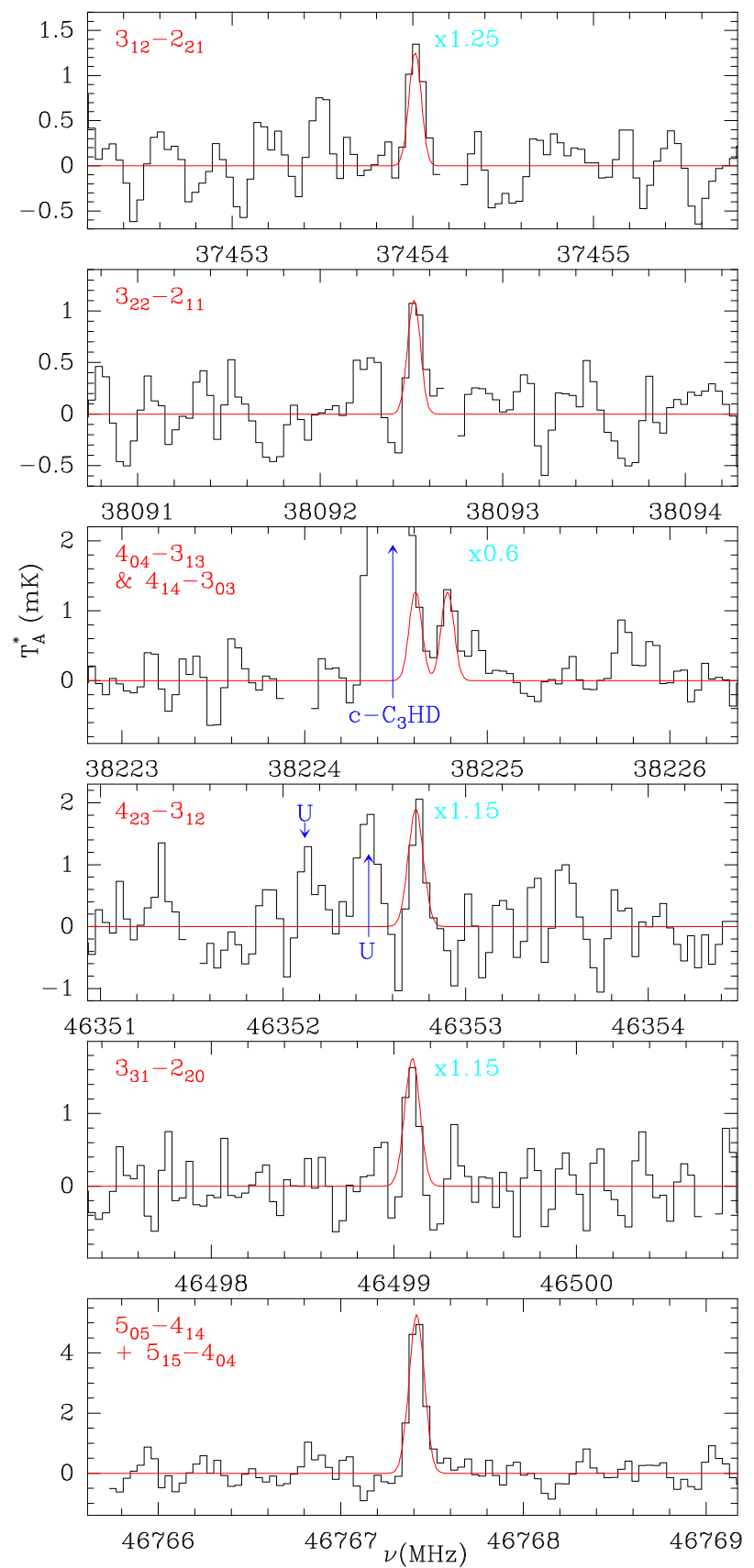

Fig. 3. Same as Fig. 2 but for the observed transitions of $c-\mathrm{C}_{5} \mathrm{H}_{6}$ towards TMC-1. The red line shows the computed synthetic spectrum for cyclopentadiene assuming $T_{\mathrm{r}}=10 \mathrm{~K}$ and $N\left(c-\mathrm{C}_{5} \mathrm{H}_{6}\right)=1.2 \times 10^{13} \mathrm{~cm}^{-2}$. Cyan labels, when present, indicate the multiplicative factor applied to the best fit model to match the observations.

of $\sim 100 \mathrm{kHz}$. Its dipole moment is also relatively low, with $\mu_{a}=0.50 \mathrm{D}$ and $\mu_{b}=0.37 \mathrm{D}$ (Caminati 1993). Frequency predictions in the $31-50 \mathrm{GHz}$ range have uncertainties between 10 and $80 \mathrm{kHz}$. We searched for indene in our data and found a large number of lines above the $3 \sigma$ level. Nineteen of them are shown in Fig. 4. Line parameters for all 47 observed lines of indene detected in TMC-1 are given in Table A.1. Improved rotational and distortion constants for indene are provided in Appendix $\mathrm{C}$ and Table C.2.

In order to derive a column density for indene, we have assumed that the rotational temperature is $10 \mathrm{~K}$. Taking the large geometrical section of the molecule and its low dipole moment into account, this assumption seems reasonable. The model fit procedure, consisting of a fit to the observed line profiles, provides a column density for indene of $(1.6 \pm 0.3) \times 10^{13} \mathrm{~cm}^{-2}$, which is very similar to that of cyclopentadiene, vinyl acetylene, and allenyl acetylene, and only a factor of five below that of $c-\mathrm{C}_{3} \mathrm{H}_{2}$. The fractional abundance of indene relative to $\mathrm{H}_{2}$ is thus $1.6 \times 10^{-9}$. The discovery of this large hydrocarbon through the old-fashioned line-by-line detection procedure is solid and robust. For this species, the observed averaged value of the line width is close to $1.0 \mathrm{~km} \mathrm{~s}^{-1}$, similar to that of $\mathrm{c}-\mathrm{CH}_{3} \mathrm{CCH}$. Most lines of polar species have line widths of $0.6 \mathrm{~km} \mathrm{~s}^{-1}$. In the case of indene, its low dipole moment and its easily thermalized conditions could favour the emission from the less dense regions of the cloud. This could suggest that this species prevails in the molecular envelope of TMC-1. However, $\mathrm{c}-\mathrm{CH}_{3} \mathrm{CCH}$ has a larger dipole moment and requires a high density to be close to thermalization, as derived in Sect. 3.1. Further observations with a higher spectral resolution are needed to discriminate between excitation and possible contribution from different cloud components.

\section{Discussion}

\section{1. $\mathrm{C}-\mathrm{C}_{3} \mathrm{HCCH}$}

The most obvious route to $c-\mathrm{C}_{3} \mathrm{HCCH}$ is the reaction between $\mathrm{CCH}$ and $c-\mathrm{C}_{3} \mathrm{H}_{2}$. To our knowledge, this reaction has not been studied either experimentally or theoretically, but it is likely that it occurs quickly at low temperatures, with the $\mathrm{H}$ loss channel being the main channel, based on the reactivity of $\mathrm{CCH}$ with other unsaturated hydrocarbons (Vakhtin et al. 2001). In addition, the two reactants are quite abundant in TMC-1 (e.g. Agúndez \& Wakelam 2013). If we implement this reaction with a rate coefficient of $10^{-10} \mathrm{~cm}^{3} \mathrm{~s}^{-1}$ in a chemical model similar to that presented by Agúndez et al. (2021) and we assume that $c-\mathrm{C}_{3} \mathrm{HCCH}$ is mostly destroyed by reactions with $\mathrm{C}$ atoms and $\mathrm{C}^{+}$and $\mathrm{H}^{+}$ions, the peak abundance calculated for $c-\mathrm{C}_{3} \mathrm{HCCH}$ is $\sim 5 \times 10^{-11}$ relative to $\mathrm{H}_{2}$, which is in very good agreement with the value observed in TMC-1. Although the subset of reactions involving $c-\mathrm{C}_{3} \mathrm{HCCH}$ is clearly incomplete, this exercise shows that the reaction $\mathrm{CCH}+c-\mathrm{C}_{3} \mathrm{H}_{2}$ could be a plausible formation route for this cyclic hydrocarbon in TMC-1. Other reactions that could also yield $c-\mathrm{C}_{3} \mathrm{HCCH}$ are $c-\mathrm{C}_{3} \mathrm{H}+\mathrm{C}_{2} \mathrm{H}_{2}$ and $\mathrm{C}_{2}+\mathrm{CH}_{2} \mathrm{CCH}$, although little is known about their chemical kinetics.

Similarly to $\mathrm{CCH}$, the radical $\mathrm{CN}$ has also been found to react rapidly with unsaturated hydrocarbons at low temperatures (e.g. Sims et al. 1993). Therefore, the reaction between $\mathrm{CN}$ and $c-\mathrm{C}_{3} \mathrm{H}_{2}$ is a very likely source of $c-\mathrm{C}_{3} \mathrm{HCN}$, which is the cyanide derivative analogue of $c-\mathrm{C}_{3} \mathrm{HCCH}$. It is interesting to note that ethynyl derivatives are more abundant than cyanide derivatives in TMC-1; for example, $\mathrm{CH}_{3} \mathrm{CCCCH} / \mathrm{CH}_{3} \mathrm{CCCN}=7.6$ and $\mathrm{CH}_{2} \mathrm{CCHCCH} / \mathrm{CH}_{2} \mathrm{CCHCN}=4.4$ (Marcelino et al. 2021; Cernicharo et al. 2021b), which is thought to reflect the $\mathrm{CCH} / \mathrm{CN}$ abundance ratio of 10 observed in this source (Pratap et al. 1997). Therefore, we could expect $c-\mathrm{C}_{3} \mathrm{HCN}$ to be a few times less abundant than $c-\mathrm{C}_{3} \mathrm{HCCH}$. We do not detect $c$ $\mathrm{C}_{3} \mathrm{HCN}$ in our sensitive TMC-1 data, which means that it must have a column density below $2.5 \times 10^{11} \mathrm{~cm}^{-2}(3 \sigma$ upper limit; see Appendix B). Therefore, the abundance ratio $c-\mathrm{C}_{3} \mathrm{HCCH} / c$ $\mathrm{C}_{3} \mathrm{HCN}$ in TMC-1 must be $>1.2$. It is therefore likely that a reduced noise level from deeper observations can lead to the detection of $c-\mathrm{C}_{3} \mathrm{HCN}$ in TMC-1. 

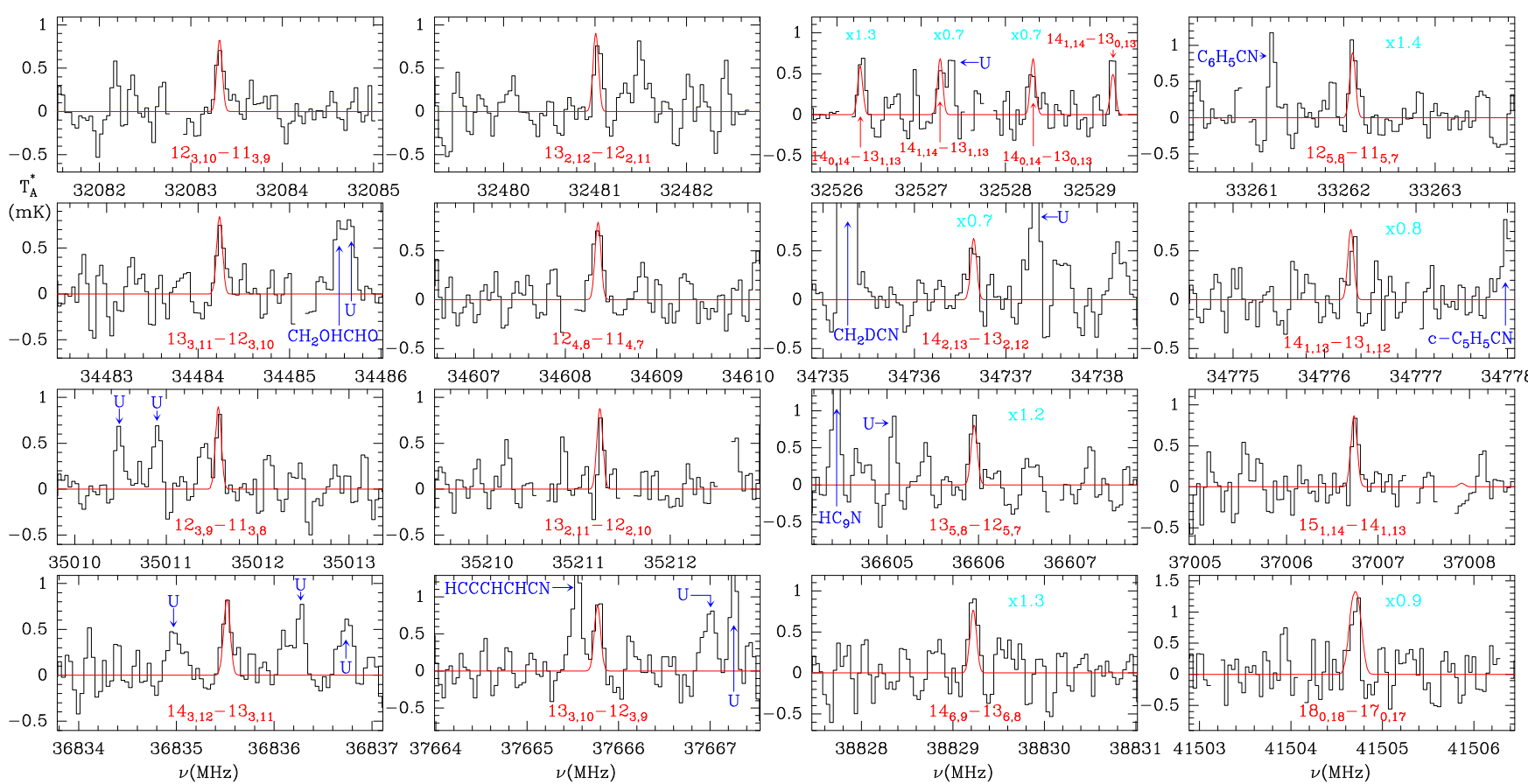

Fig. 4. Same as Fig. 2 but for the selected transitions of $c-\mathrm{C}_{9} \mathrm{H}_{8}$ observed towards TMC-1. The red line shows the computed synthetic spectrum for indene assuming $T_{\mathrm{r}}=10 \mathrm{~K}$ and $N\left(c-\mathrm{C}_{9} \mathrm{H}_{8}\right)=1.6 \times 10^{13} \mathrm{~cm}^{-2}$. Cyan labels, when present, indicate the multiplicative factor applied to the best fit model to match the observations.

\subsection{Cyclopentadiene $\left(c-\mathrm{C}_{5} \mathrm{H}_{6}\right)$}

Given the high abundance derived for cyclopentadiene in TMC$1,1.2 \times 10^{-9}$ relative to $\mathrm{H}_{2}$, it is not straightforward to find an efficient formation route. Several reactions that could lead to $c-\mathrm{C}_{5} \mathrm{H}_{6}$ are not efficient under the cold conditions of TMC1. For example, the reaction $\mathrm{CH}_{2} \mathrm{CCH}+\mathrm{C}_{2} \mathrm{H}_{4}$ has an activation barrier (Saeys et al. 2003), while the reactions of $\mathrm{C}_{2} \mathrm{H}_{3}$ with either $\mathrm{CH}_{3} \mathrm{CCH}$ or $\mathrm{CH}_{2} \mathrm{CCH}_{2}$ probably also have barriers, as occurs in other reactions of $\mathrm{C}_{2} \mathrm{H}_{3}$ with unsaturated hydrocarbons (Miller et al. 2000; Ismail et al. 2007; Goldsmith et al. 2009). The reaction between $\mathrm{C}_{3} \mathrm{H}_{5}$ and $\mathrm{C}_{2} \mathrm{H}_{2}$ yields cyclopentadiene, but it has a barrier (Bouwman et al. 2015). The reaction $\mathrm{C}_{2} \mathrm{H}+\mathrm{CH}_{2} \mathrm{CHCH}_{3}$ is fast at low temperatures and produces several $\mathrm{C}_{5} \mathrm{H}_{6}$ isomers, although the experimental data seem to be inconsistent with cyclopentadiene being one of them (Bouwman et al. 2012).

The reaction between $\mathrm{CH}$ and butadiene $\left(\mathrm{CH}_{2} \mathrm{CHCHCH}_{2}\right)$ is calculated to produce $c-\mathrm{C}_{5} \mathrm{H}_{6}$ with no barrier (McCarthy et al. 2021). Adopting a rate coefficient of $10^{-10} \mathrm{~cm}^{3} \mathrm{~s}^{-1}$ for this reaction in our chemical model, based on Agúndez et al. (2021) and assuming that $c-\mathrm{C}_{5} \mathrm{H}_{6}$ is mostly removed through reactions with $\mathrm{C}$ atoms and $\mathrm{C}^{+}$and $\mathrm{H}^{+}$ions, we calculate a peak abundance of $\sim 3 \times 10^{-13}$ relative to $\mathrm{H}_{2}$ for $c-\mathrm{C}_{5} \mathrm{H}_{6}$. This is more than three orders of magnitude below the observed value. In the chemical model, butadiene is essentially formed by the reaction $\mathrm{CH}+\mathrm{CH}_{2} \mathrm{CHCH}_{3}$ (Daugey et al. 2005; Loison \& Bergeat 2009; Ribeiro \& Mebel 2016), with a peak abundance of $\sim 3 \times 10^{-10}$ relative to $\mathrm{H}_{2}$. Butadiene is an interesting potential precursor of $c-\mathrm{C}_{5} \mathrm{H}_{6}$, as well as of benzene (Jones et al. 2011), but to play such a role it needs to have an abundance much higher than that calculated by current gas-phase chemical models. Unfortunately, it is a non-polar molecule and thus cannot be detected through radio techniques.

Given the radical $\mathrm{CH}_{2} \mathrm{CCH}$ (Agúndez et al. 2021), reactions between radicals, such as $\mathrm{CH}_{2} \mathrm{CCH}+\mathrm{C}_{2} \mathrm{H}_{5}$ and $\mathrm{C}_{2} \mathrm{H}_{3}$
$+\mathrm{CH}_{2} \mathrm{CHCH}_{2}$, are also potential sources of $c-\mathrm{C}_{5} \mathrm{H}_{6}$. Routes involving ions, such as condensation reactions between cationic and neutral hydrocarbons (Herbst \& Leung 1989), may also lead to $c-\mathrm{C}_{5} \mathrm{H}_{6}$. Theoretical studies on these reactions would help to evaluate their role in the synthesis of cyclopentadiene. Whatever the formation route to $c-\mathrm{C}_{5} \mathrm{H}_{6}$ is, this hydrocarbon cycle is the most obvious precursor of the two cyanide derivatives of $c-\mathrm{C}_{5} \mathrm{H}_{5} \mathrm{CN}$ detected in TMC-1 (McCarthy et al. 2021; Lee et al. 2021).

\subsection{Indene $\left(\mathrm{c}-\mathrm{C}_{9} \mathrm{H}_{8}\right)$}

The high abundance derived for this aromatic molecule, in fact the first pure PAH found in space, challenges us to determine an efficient formation route in TMC-1. Such a route should involve a fast reaction between two abundant species. Potential formation reactions such as $c-\mathrm{C}_{6} \mathrm{H}_{6}+\mathrm{CH}_{2} \mathrm{CCH}$ and $c-\mathrm{C}_{6} \mathrm{H}_{5}+\mathrm{C}_{3} \mathrm{H}_{4}$ have activation barriers (Kislov \& Mebel 2007; Vereecken \& Peeters 2003; Mebel et al. 2017). Reactions such as $c-\mathrm{C}_{5} \mathrm{H}_{6}+\mathrm{C}_{4} \mathrm{H}_{3}$ or $c-\mathrm{C}_{5} \mathrm{H}_{5}+\mathrm{C}_{4} \mathrm{H}_{4}$ could be efficient at producing indene. Doddipatla et al. (2021) suggest that indene can be formed through the barrier-less reaction between the radical $\mathrm{CH}$ and styrene $\left(c-\mathrm{C}_{6} \mathrm{H}_{5} \mathrm{C}_{2} \mathrm{H}_{3}\right)$. However, it is unknown whether the precursor styrene is sufficiently abundant in TMC1 , and it is not obvious which formation pathway can lead to it. Doddipatla et al. (2021) present a tentative synthetic route, from which they calculate abundances of up to $10^{-12}$ for indene, well below the value derived from observations here. It is clear that further research is needed to explain the presence of indene in TMC-1 with an abundance as high as $1.6 \times 10^{-9}$ relative to $\mathrm{H}_{2}$.

\section{Conclusions}

We report the detection of $c-\mathrm{C}_{3} \mathrm{HCCH}$, cyclopentadiene, and indene in TMC-1. While the observed abundance of $c-\mathrm{C}_{3} \mathrm{HCCH}$, 
a few $10^{-11}$ relative to $\mathrm{H}_{2}$, can be accounted for by the reaction between $\mathrm{CCH}$ and $c-\mathrm{C}_{3} \mathrm{H}_{2}$, the fairly high abundances found for cyclopentadiene and indene, above $10^{-9}$, are difficult to explain using the formation routes that have been proposed thus far. The detection of very abundant cyclopentadiene and indene should drive further research to elucidate which plausible bottom-up mechanisms of the formation of such complex aromatic hydrocarbons can be at work in cold dense clouds such as TMC- 1 .

Acknowledgements. We thank ERC for funding through grant ERC2013-Syg-610256-NANOCOSMOS. We also thank Ministerio de Ciencia e Innovación of Spain (MICIU) for funding support through projects AYA2016-75066-C2-1-P, PID2019-106110GB-I00, PID2019-107115GBC21/AEI/10.13039/501100011033, and PID2019-106235GB-I00. M.A. thanks MICIU for grant RyC-2014-16277. We would like to thank our referee, S. Yamamoto, for his useful comments and suggestions.

\section{References}

Agúndez, M., \& Wakelam, V. 2013, Chem. Rev., 113, 8710

Agúndez, M., Cabezas, C., Tercero, B., et al. 2021, A\&A, 647, L10

Allamandola, L. J., Tielens, A. G. G. M., \& Barker, J. R. 1985, ApJ, 290, L25

Avery, L. W., \& Green, S. 1989, ApJ, 337, 306

Benson, R. C., \& Flygare, W. H. 1970, J. Am. Chem. Soc., 92, 7223

Bogey, M., Demuynck, C., \& Destombes, J. L. 1988, J. Mol. Spectrosc., 132, 277

Bouwman, J., Goulay, F., Leone, S. R., \& Wilson, K. R. 2012, J. Phys. Chem. A, 116, 3907

Bouwman, J., Bodi, A., Oomens, J., \& Hemberger, P. 2015, Phys. Chem. Chem. Phys., 17, 20508

Burkhardt, A. M. 2021, et al., ApJ, submitted

Cabezas, C., Endo, Y., Roueff, E., et al. 2021, A\&A, 646, L1

Caminati, W. 1993, J. Chem. Soc. Faraday Trans., 89, 4153

Cernicharo, J. 2004, ApJ, 608, L41

Cernicharo, J. 2012, in ECLA 2011: Proc. of the European Conference on Laboratory Astrophysics, eds. C. Stehl, C. Joblin, \& L. d'Hendecourt (Cambridge: Cambridge University Press), EAS Publ. Ser., 251

Cernicharo, J., \& Guélin, M. 1987, A\&A, 176, 299

Cernicharo, J., Guélin, M., \& Kahane, C. 2000, A\&AS, 142, 181

Cernicharo, J., Heras, A. M., Tielens, A. G. G. M., et al. 2001, ApJ, 546, L123

Cernicharo, J., Guélin, M., Agúndez, M., et al. 2018, A\&A, 618, A4

Cernicharo, J., Marcelino, N., Pardo, J. R., et al. 2020a, A\&A, 641, L9

Cernicharo, J., Marcelino, N., Agúndez, M., et al. 2020b, A\&A, 642, L8

Cernicharo, J., Marcelino, N., Agúndez, M., et al. 2020c, A\&A, 642, L17

Cernicharo, J., Agúndez, M., Cabezas, C., et al. 2021a, A\&A, 647, L2

Cernicharo, J., Agúndez, M., Cabezas, C., et al. 2021b, A\&A, 647, L3

Cernicharo, J., Cabezas, C., Endo, Y., et al. 2021c, A\&A, 646, L3

Cherchneff, I., Barker, J. R., \& Tielens, A. G. G. M. 1992, ApJ, 401, 269

Daugey, N., Caubet, P., Retail, B., et al. 2005, Phys. Chem. Chem. Phys., 7, 2921

Doddipatla, S., Galimova, G. R., Wei, H., et al. 2021, Sci. Adv., 7, eabd4044

Fossé, D., Cernicharo, J., Gerin, M., \& Cox, P. 2001, ApJ, 552, 168
Goldsmith, C. F., Ismail, H., Abel, P. R., \& Green, W. H. 2009, Proc. Combust. Inst., 32, 139

Gottlieb, C. A., McCarthy, M. C., Gordon, V. D., et al. 1998, ApJ, 509, L141

Herbst, E., \& Leung, C. M. 1989, ApJS, 69, 271

Ismail, H., Goldsmith, C. F., Abel, P. R., et al. 2007, J. Phys. Chem. A, 111, 6843

Joblin, C., \& Cernicharo, J. 2018, Science, 359, 156

Jones, B. M., Zhang, F., Kaiser, R. I., et al. 2011, Proc. Natl. Acad. Sci., 108, 452

Kaifu, N., Ohishi, M., Kawaguchi, K., et al. 2004, PASJ, 56, 69

Khalifa, M. B., Sahnoun, E., Wiesenfeld, L., et al. 2019, Phys. Chem. Chem. Phys., 21, 1443

Kislov, V. V., \& Mebel, A. M. 2007, J. Phys. Chem. A, 111, 3922

Laurie, V. 1956, J. Chem. Phys., 24, 635

Lee, K. L. L., Changala, P. B., Loomis, R. A., et al. 2021, ApJ, 910, L2

Léger, A., \& Puget, J. L. 1984, A\&A, 137, L5

Li, Y. S., Jalilian, M. R., \& Durig, J. R. 1979, J. Mol. Struct., 51, 171

Loison, J.-C., \& Bergeat, A. 2009, Phys. Chem. Chem. Phys., 11, 655

McGuire, B. A., Burkhardt, A. M., Kalenskii, S., et al. 2018, Science, 359, 202

McGuire, B. A., Loomis, R. A., Burkhardt, A. M., et al. 2021, Science, 371, 1265

Mangum, J. G., \& Wooten, A. 1990, A\&A, 239, 319

Marcelino, N., Cernicharo, J., \& Agúndez, M. 2007, ApJ, 665, L127

Marcelino, N., Agúndez, M., Tercero, B., et al. 2020, A\&A, 643, L6

Marcelino, N., Tercero, B., Agúndez, M., \& Cernicharo, J. 2021, A\&A, 646, L9

Martínez, L., Santoro, G., Merino, P., et al. 2020, Nat. Astron., 4, 97

Matthews, H. E., \& Irvine, W. M. 1985, ApJ, 298, L61

Matthews, H. E., Madden, S. C., Avery, L. W., \& Irvine, W. M. 1986, ApJ, 307, L69

McCarthy, M. C., Travers, M. J., Kovacs, A., et al. 1997, Science, 275, 518

McCarthy, M. C., Grabow, J.-U., Travers, M. J., et al. 1999, ApJ, 513, 305

McCarthy, M. C., Lee, K. L. K., Loomis, R. A., et al. 2021, Nat. Astron., 5, 176

Mebel, A. M., Landera, A., \& Kaiser, R. I. 2017, J. Phys. Chem. A, 121, 901

Miller, J. A., Klippenstein, S. J., \& Robertson, S. H. 2000, J. Phys. Chem. A, 104,7525

Müller, H. S. P., Schlöder, F., Stutzki, J., \& Winnewisser, G. 2005, J. Mol. Struct., 742,215

Pickett, H. M., Poynter, R. L., Cohen, E. A., et al. 1998, J. Quant. Spectrosc. Radiat. Transf., 60, 883

Pilleri, P., Joblin, C., Boulanger, F., \& Onaka, T. 2015, A\&A, 577, A16

Pratap, P., Dickens, J. E., Snell, R. L., et al. 1997, ApJ, 486, 862

Ribeiro, J. M., \& Mebel, A. M. 2016, J. Phys. Chem. A, 120, 1800

Saeys, M., Reyniers, M.-F., Marin, G. B., et al. 2003, J. Phys. Chem. A, 107, 9147

Scharpen, L. H., \& Laurie, V. 1965, J. Chem. Phys., 43, 2765

Seburg, R. A., McMahon, R. J., Stanton, J. F., \& Gauss, J. 1997, J. Am. Chem. Soc., 119, 10838

Sims, I. R., Queffelec, J.-L., Travers, D., et al. 1993, Chem. Phys. Lett., 211, 461

Tercero, F., López-Pérez, J. A., Gallego, J. D., et al. 2021, A\&A, 645, A37

Travers, M. J., McCarthy, M. C., Gottlieb, C. A., \& Thaddeus, P. 1997, ApJ, 483, L135

Turner, B. E., Herbst, E., \& Terzieva, R. 2000, ApJS, 126, 427

Vakhtin, A. B., Heard, D. E., Smith, I. W. M., \& Leone, S. R. 2001, Chem. Phys. Lett., 344, 317

Vereecken, L., \& Peeters, J. 2003, Phys. Chem. Chem. Phys., 5, 2807

Woods, P. M., Millar, T. J., \& Zijlstra, A. A. 2002, ApJ, 574, L167

Yamamoto, S., Saito, S., Ohishi, M., et al. 1987, ApJ, 322, L55 
Appendix A: Line parameters of $c-\mathrm{C}_{3} \mathrm{HCCH}, c-\mathrm{C}_{5} \mathrm{H}_{6}$, and $c-\mathrm{C}_{9} \mathrm{H}_{8}$

Line parameters for the different molecules studied in this work were obtained by fitting a Gaussian line profile to the observed data. A window of $\pm 15 \mathrm{~km} \mathrm{~s}^{-1}$ around the local standard of rest velocity of the source was considered for each transition. The derived line parameters for the three molecular species discovered in this work are given in Table A.1.

Table A.1. Observed line parameters for $c-\mathrm{C}_{3} \mathrm{HCCH}$ in TMC-1.

\begin{tabular}{|c|c|c|c|c|c|}
\hline$J_{K_{a}, K_{c}}$ & $\begin{array}{l}v_{\mathrm{obs}}(a) \\
(\mathrm{MHz})\end{array}$ & $\begin{array}{l}\int T_{\mathrm{A}}^{*} \mathrm{~d} v^{(b)} \\
\left(\mathrm{mK} \mathrm{km} \mathrm{s}^{-1}\right)\end{array}$ & $\begin{array}{l}\Delta v^{(c)} \\
\left(\mathrm{km} \mathrm{s}^{-1}\right)\end{array}$ & $\begin{array}{l}T_{\mathrm{A}}^{*(d)} \\
(\mathrm{mK})\end{array}$ & \\
\hline \multicolumn{6}{|l|}{$c-\mathrm{C}_{3} \mathrm{HCCH}$} \\
\hline $1_{1,0}-1_{0,1}$ & $31525.012 \pm 0.03$ & $1.30 \pm 0.23$ & $1.35 \pm 0.28$ & $0.90 \pm 0.20$ & \\
\hline $2,1,1-2,1$ & $31838.475 \pm 0.03$ & $1.98 \pm 0.34$ & $1.34 \pm 0.20$ & $1.38 \pm 0.24$ & \\
\hline $5_{1,5}-4_{1,4}$ & $31904.045 \pm 0.03$ & $0.53 \pm 0.18$ & $0.76 \pm 0.35$ & $0.65 \pm 0.24$ & A \\
\hline $3_{1,2}-3_{0,3}$ & $32312.929 \pm 0.03$ & $0.87 \pm 0.16$ & $0.87 \pm 0.17$ & $0.93 \pm 0.20$ & $\mathrm{~A}$ \\
\hline $9_{0,9}-8_{1,8}$ & $32429.470 \pm 0.03$ & $0.88 \pm 0.20$ & $1.13 \pm 0.28$ & $0.73 \pm 0.21$ & \\
\hline $5_{0,5}-4_{0,4}$ & $32646.191 \pm 0.03$ & $1.34 \pm 0.19$ & $1.32 \pm 0.24$ & $0.95 \pm 0.18$ & \\
\hline $4_{1,3}-4_{0,4}$ & $32953.663 \pm 0.03$ & $1.07 \pm 0.22$ & $1.16 \pm 0.33$ & $0.87 \pm 0.22$ & \\
\hline $5_{1,4}-4_{1,3}$ & $33460.002 \pm 0.03$ & $0.70 \pm 0.20$ & $0.40 \pm 0.23$ & $1.35 \pm 0.22$ & $\mathrm{~B}$ \\
\hline $5_{1,4}-5_{0,5}$ & $33767.455 \pm 0.03$ & $1.24 \pm 0.23$ & $1.18 \pm 0.24$ & $0.88 \pm 0.21$ & \\
\hline $6_{1,5}-6_{0,6}$ & $34762.885 \pm 0.03$ & $1.09 \pm 0.25$ & $1.37 \pm 0.38$ & $0.75 \pm 0.21$ & \\
\hline $7_{1,6}-7_{0,7}$ & $35950.042 \pm 0.02$ & & & & $\mathrm{C}$ \\
\hline $8_{1,7}-8_{0,8}$ & $37340.311 \pm 0.02$ & & & & $\mathrm{D}$ \\
\hline $1_{1,1}-0_{0,0}$ & $37752.281 \pm 0.01$ & & & & $\mathrm{E}$ \\
\hline $6_{1,6}-5_{1,5}$ & $38278.543 \pm 0.01$ & & & & $\mathrm{C}$ \\
\hline $9_{1,8}-9_{0,9}$ & $38946.462 \pm 0.03$ & & & & $\mathrm{E}$ \\
\hline $6_{0,6}-5_{0,5}$ & $39149.938 \pm 0.03$ & $0.75 \pm 0.15$ & $0.87 \pm 0.16$ & $0.80 \pm 0.21$ & \\
\hline $10_{0,10}-9_{1,9}$ & $40056.165 \pm 0.03$ & $1.06 \pm 0.18$ & $0.81 \pm 0.20$ & $1.23 \pm 0.21$ & \\
\hline $2_{1,2}-1_{0,1}$ & $43979.464 \pm 0.03$ & $0.98 \pm 0.18$ & $0.96 \pm 0.19$ & $0.95 \pm 0.26$ & \\
\hline \multicolumn{6}{|l|}{$c-\mathrm{C}_{5} \mathrm{H}_{6}{ }^{(f)}$} \\
\hline $3_{1,2}-2_{2,1}$ & $37454.017 \pm 0.02$ & $1.18 \pm 0.22$ & $0.79 \pm 0.16$ & $1.40 \pm 0.30$ & \\
\hline $3_{2,2}-2,1$ & $38092.525 \pm 0.02$ & $0.85 \pm 0.17$ & $0.68 \pm 0.15$ & $1.17 \pm 0.24$ & \\
\hline $4_{0,4}-3_{1,3}$ & $38224.588^{(e)}$ & & & & $\mathrm{F}$ \\
\hline $4_{1,4}-3_{0,3}$ & $38224.787 \pm 0.02$ & $0.75 \pm 0.14$ & $0.68 \pm 0.15$ & $1.03 \pm 0.20$ & \\
\hline $4_{1,3}-3_{2,2}$ & $46314.423^{(e)}$ & & & $\leq 1.5$ & \\
\hline $4_{2,3}-3_{1,2}$ & $46352.738 \pm 0.02$ & $1.37 \pm 0.26$ & $0.56 \pm 0.12$ & $2.33 \pm 0.47$ & \\
\hline $3_{3,1}-22,0$ & $46499.116 \pm 0.02$ & $0.91 \pm 0.18$ & $0.48 \pm 0.09$ & $1.78 \pm 0.36$ & \\
\hline $5_{0,5}-4_{1,4}$ & $46767.415 \pm 0.02$ & $3.49 \pm 0.23$ & $0.62 \pm 0.05$ & $5.33 \pm 0.39$ & $\mathrm{G}$ \\
\hline \multicolumn{6}{|l|}{$c-\mathrm{C}_{9} \mathrm{H}_{8}(f)$} \\
\hline $11_{4,7}-10_{4,6}$ & $31364.868 \pm 0.02$ & $0.47 \pm 0.20$ & $1.12 \pm 0.39$ & $0.40 \pm 0.20$ & \\
\hline $12_{3,10}-11_{3,9}$ & $32083.322 \pm 0.01$ & $0.80 \pm 0.18$ & $1.11 \pm 0.32$ & $0.68 \pm 0.18$ & \\
\hline $11_{3,8}-10_{3,7}$ & $32171.624 \pm 0.01$ & $0.83 \pm 0.28$ & $0.89 \pm 0.33$ & $0.88 \pm 0.20$ & \\
\hline $13_{2,12}-12_{2,11}$ & $32481.036 \pm 0.01$ & $0.74 \pm 0.16$ & $0.83 \pm 0.18$ & $0.84 \pm 0.21$ & \\
\hline $14_{0,14}-13_{1,13}$ & $32526.303 \pm 0.01$ & $0.94 \pm 0.20$ & $1.01 \pm 0.24$ & $0.87 \pm 0.18$ & \\
\hline $14_{1,14}-13_{1,13}$ & $32527.242 \pm 0.01$ & $0.78 \pm 0.21$ & $1.05 \pm 0.33$ & $0.70 \pm 0.18$ & \\
\hline $14_{0,14}-13_{0,13}$ & $32528.322 \pm 0.01$ & $1.14 \pm 0.21$ & $1.65 \pm 0.15$ & $0.65 \pm 0.18$ & \\
\hline $14_{1,14}-13_{0,13}$ & $32529.269 \pm 0.01$ & $0.61 \pm 0.19$ & $0.60 \pm 0.24$ & $0.97 \pm 0.20$ & \\
\hline $13_{1,12}-12_{1,11}$ & $32555.319 \pm 0.03$ & $1.15 \pm 0.26$ & $1.87 \pm 0.45$ & $0.57 \pm 0.20$ & A \\
\hline $12_{2,10}-11_{2,9}$ & $33087.091 \pm 0.02$ & $0.21 \pm 0.11$ & $0.48 \pm 0.20$ & $0.40 \pm 0.16$ & \\
\hline $12_{6,7}-11_{6,6}$ & $33104.538 \pm 0.01$ & & & $\leq 0.48$ & \\
\hline
\end{tabular}

Notes. ${ }^{(a)}$ Observed frequency assuming a $v_{\mathrm{LSR}}$ of $5.83 \mathrm{~km} \mathrm{~s}^{-1} \cdot{ }^{(b)}$ Integrated line intensity (in $\left.\mathrm{mK} \mathrm{km} \mathrm{s}{ }^{-1}\right) .{ }^{(c)}$ Line width at half intensity derived by fitting a Gaussian function to the observed line profile (in $\mathrm{km} \mathrm{s}^{-1}$ ). ${ }^{(d)}$ Antenna temperature (in $\mathrm{mK}$ ). ${ }^{(e)}$ Predicted frequency. ${ }^{(f)}$ Measured frequencies assuming a $v_{\mathrm{LSR}}$ of $5.83 \mathrm{~km} \mathrm{~s}^{-1}$. The difference between the observed and predicted frequencies is $\pm 15 \mathrm{kHz}$. ${ }^{(A)}$ Partially blended with another feature. Fit still possible, providing reasonable results. ${ }^{(B)}$ Blended with another feature. Fit uncertain. ${ }^{(C)}$ Fully blended with a negative feature produced in the frequency switching folding. Fit unreliable. Frequency corresponds to the predicted value from the rotational constants of Table C.1. ${ }^{(B)}$ Fully blended with a line from $\mathrm{HCCCH}_{2} \mathrm{CN}$. Frequency corresponds to the predicted value from the rotational constants of Table C.1. ${ }^{(E)} \mathrm{A}$ narrow line is clearly visible, but it is affected by a negative feature. Frequency corresponds to the predicted value from the rotational constants of Table C.1. ${ }^{(F)}$ Fully blended with a line from $c-C_{3}$ HD. Frequency corresponds to the predicted value. ${ }^{(G)}$ The $5_{1,5}-4_{04}$ line, which belongs to the para species, is fully blended with the $5_{0,5}-4_{1,4}$ transition of the ortho species. Both lines have similar line strengths. ${ }^{(H)}$ Unresolved doublet. 
Table A.1. continued.

\begin{tabular}{|c|c|c|c|c|c|}
\hline$J_{K_{a}, K_{c}}$ & $\begin{array}{l}v_{\mathrm{obs}}(a) \\
(\mathrm{MHz})\end{array}$ & $\begin{array}{l}\int T_{\mathrm{A}}^{*} \mathrm{~d} v^{(b)} \\
\left(\mathrm{mK} \mathrm{km} \mathrm{s}^{-1}\right)\end{array}$ & $\begin{array}{l}\Delta v^{(c)} \\
\left(\mathrm{km} \mathrm{s}^{-1}\right)\end{array}$ & $\begin{array}{l}T_{\mathrm{A}}^{*}(d) \\
(\mathrm{mK})\end{array}$ & \\
\hline $12_{4,9}-11_{4,8}$ & $33105.876 \pm 0.02$ & $0.30 \pm 0.16$ & $0.40 \pm 0.20$ & $0.45 \pm 0.16$ & \\
\hline $12_{6,6}-11_{6,5}$ & $33124.468 \pm 0.02$ & $0.56 \pm 0.17$ & $0.84 \pm 0.19$ & $0.70 \pm 0.19$ & A \\
\hline $12_{5,8}-11_{5,7}$ & $33262.106 \pm 0.01$ & $0.91 \pm 0.18$ & $0.81 \pm 0.20$ & $1.05 \pm 0.22$ & \\
\hline $12_{5,7}-11_{5,6}$ & $33524.184 \pm 0.02$ & $0.26 \pm 0.10$ & $0.34 \pm 0.20$ & $0.72 \pm 0.18$ & \\
\hline $13_{3,11}-12_{3,10}$ & $34484.248 \pm 0.01$ & $0.72 \pm 0.16$ & $0.96 \pm 0.26$ & $0.70 \pm 0.18$ & \\
\hline $12_{4,8}-11_{4,7}$ & $34608.352 \pm 0.01$ & $0.88 \pm 0.16$ & $1.11 \pm 0.22$ & $0.75 \pm 0.18$ & \\
\hline $14_{2,13}-13_{2,12}$ & $34736.637 \pm 0.01$ & $0.60 \pm 0.19$ & $1.02 \pm 0.36$ & $0.55 \pm 0.21$ & \\
\hline $15_{0,15}-14_{1,14}$ & $34771.228 \pm 0.02$ & & & $\leq 0.45$ & \\
\hline $15_{1,15}-14_{1,14}$ & $34771.684 \pm 0.02$ & $0.30 \pm 0.08$ & $0.54 \pm 0.17$ & $0.53 \pm 0.15$ & \\
\hline $15_{0,15}-14_{0,14}$ & $34772.190 \pm 0.02$ & $0.49 \pm 0.32$ & $0.94 \pm 0.33$ & $0.49 \pm 0.15$ & A \\
\hline $15_{1,15}-14_{0,14}$ & $34772.612 \pm 0.02$ & & & $\leq 0.45$ & \\
\hline $14_{1,13}-13_{1,12}$ & $34776.320 \pm 0.02$ & $0.40 \pm 0.08$ & $0.33 \pm 0.15$ & $1.13 \pm 0.17$ & \\
\hline $12_{3,9}-11_{3,8}$ & $35011.580 \pm 0.01$ & $0.57 \pm 0.13$ & $0.63 \pm 0.15$ & $0.85 \pm 0.19$ & \\
\hline $13_{2,11}-12_{2,10}$ & $35211.250 \pm 0.01$ & $0.43 \pm 0.08$ & $0.49 \pm 0.22$ & $0.82 \pm 0.17$ & \\
\hline $13_{4,10}-12_{4,9}$ & $35766.651 \pm 0.02$ & $0.68 \pm 0.17$ & $1.12 \pm 0.26$ & $0.57 \pm 0.19$ & \\
\hline $13_{6,8}-12_{6,7}$ & $35959.203 \pm 0.01$ & & & $\leq 0.60$ & \\
\hline $13_{6,7}-12_{6,6}$ & $36008.349 \pm 0.02$ & $0.64 \pm 0.15$ & $1.00 \pm 0.34$ & $0.60 \pm 0.20$ & A \\
\hline $13_{5,9}-12_{5,8}$ & $36101.117 \pm 0.02$ & $0.64 \pm 0.17$ & $1.10 \pm 0.40$ & $0.47 \pm 0.16$ & \\
\hline $13_{5,8}-12_{5,7}$ & $36605.949 \pm 0.01$ & $0.71 \pm 0.15$ & $0.71 \pm 0.15$ & $0.94 \pm 0.21$ & \\
\hline $14_{3,12}-13_{3,11}$ & $36835.520 \pm 0.01$ & $0.80 \pm 0.16$ & $1.02 \pm 0.25$ & $0.74 \pm 0.18$ & \\
\hline $15_{2,14}-14_{2,13}$ & $36986.145 \pm 0.02$ & $0.32 \pm 0.11$ & $0.45 \pm 0.16$ & $0.59 \pm 0.19$ & \\
\hline $15_{1,14}-14_{1,13}$ & $37006.756 \pm 0.01$ & $0.60 \pm 0.14$ & $0.65 \pm 0.16$ & $0.87 \pm 0.19$ & \\
\hline $16_{1,16}-15_{1,15}$ & $37016.001 \pm 0.02$ & $0.39 \pm 0.15$ & $0.77 \pm 0.27$ & $0.47 \pm 0.20$ & \\
\hline $16_{0,16}-15_{0,15}$ & $37016.269 \pm 0.02$ & $0.68 \pm 0.21$ & $1.05 \pm 0.35$ & $0.57 \pm 0.20$ & A \\
\hline $14_{2,12}-13_{2,11}$ & $37318.440 \pm 0.01$ & $0.30 \pm 0.12$ & $0.60 \pm 0.20$ & $0.47 \pm 0.20$ & \\
\hline $13_{3,10}-12_{3,9}$ & $37665.778 \pm 0.01$ & $0.84 \pm 0.16$ & $0.78 \pm 0.17$ & $1.01 \pm 0.21$ & \\
\hline $13_{4,9}-12_{4,8}$ & $37842.548 \pm 0.01$ & $0.41 \pm 0.16$ & $0.64 \pm 0.21$ & $0.70 \pm 0.19$ & \\
\hline $14_{4,11}-13_{4,10}$ & $38361.360 \pm 0.01$ & & & & $\mathrm{C}$ \\
\hline $14_{6,9}-13_{6,8}$ & $38829.224 \pm 0.01$ & $0.87 \pm 0.17$ & $0.83 \pm 0.16$ & $1.00 \pm 0.23$ & \\
\hline $14_{5,10}-13_{5,9}$ & $38918.551 \pm 0.01$ & & & $\leq 0.69$ & \\
\hline $14_{6,8}-13_{6,7}$ & $38939.641 \pm 0.02$ & & & $\leq 0.69$ & \\
\hline $15_{3,13}-14_{3,12}$ & $39147.950 \pm 0.02$ & $0.38 \pm 0.13$ & $0.48 \pm 0.20$ & $0.75 \pm 0.23$ & \\
\hline $16_{2,15}-15_{2,14}$ & $39232.293 \pm 0.02$ & $1.02 \pm 0.27$ & $0.68 \pm 0.19$ & $1.46 \pm 0.24$ & \\
\hline $16_{1,15}-15_{1,14}$ & $39242.748 \pm 0.02$ & & & $\leq 1.6$ & \\
\hline $17_{1,17}-16_{1,16}$ & $39260.308 \pm 0.02$ & $0.71 \pm 0.23$ & $0.54 \pm 0.18$ & $1.21 \pm 0.40$ & \\
\hline $17_{0,17}-16_{0,16}$ & $39260.513 \pm 0.02$ & $1.04 \pm 0.26$ & $0.61 \pm 0.15$ & $1.61 \pm 0.40$ & \\
\hline $15_{2,13}-14_{2,12}$ & $39447.608 \pm 0.03$ & $0.54 \pm 0.18$ & $0.82 \pm 0.29$ & $0.62 \pm 0.22$ & \\
\hline $14_{5,9}-13_{5,8}$ & $39799.463 \pm 0.03$ & $0.51 \pm 0.18$ & $1.10 \pm 0.33$ & $0.43 \pm 0.20$ & \\
\hline $14_{3,11}-13_{3,10}$ & $40118.461 \pm 0.02$ & & & $\leq 0.65$ & \\
\hline $15_{4,12}-14_{4,11}$ & $40886.724 \pm 0.03$ & $0.58 \pm 0.20$ & $0.95 \pm 0.35$ & $0.57 \pm 0.26$ & \\
\hline $14_{4,10}-13_{4,9}$ & $40983.754 \pm 0.03$ & $0.37 \pm 0.17$ & $0.60 \pm 0.29$ & $0.58 \pm 0.24$ & \\
\hline $16_{3,14}-15_{3,13}$ & $41432.310 \pm 0.03$ & & & $\leq 0.90$ & \\
\hline $17_{2,16}-16_{2,15}$ & $41476.748 \pm 0.03$ & & & & B \\
\hline $17_{1,16}-16_{1,15}$ & $41482.002 \pm 0.03$ & & & $\leq 0.90$ & \\
\hline $18_{1,18}-17_{1,17}$ & $41504.704 \pm 0.01$ & $0.95 \pm 0.20$ & $0.74 \pm 0.18$ & $1.21 \pm 0.29$ & $\mathrm{H}$ \\
\hline $18_{0,18}-17_{0,17}$ & $41504.704 \pm 0.01$ & & & & $\mathrm{H}$ \\
\hline $16_{2,14}-15_{2,13}$ & $41608.793 \pm 0.02$ & $0.63 \pm 0.27$ & $0.49 \pm 0.17$ & $1.20 \pm 0.33$ & \\
\hline $15_{5,11}-14_{5,10}$ & $41698.205 \pm 0.02$ & & & $\leq 0.90$ & \\
\hline $19_{1,19}-18_{1,18}$ & $43748.996 \pm 0.02$ & $1.00 \pm 0.30$ & $0.92 \pm 0.38$ & $1.09 \pm 0.35$ & $\mathrm{H}$ \\
\hline $19_{0,19}-18_{0,18}$ & $43748.996 \pm 0.02$ & & & & $\mathrm{H}$ \\
\hline $20_{1,20}-19_{1,19}$ & $45993.359 \pm 0.02$ & $1.24 \pm 0.31$ & $0.64 \pm 0.23$ & $1.83 \pm 0.42$ & $\mathrm{H}$ \\
\hline $20_{0,20}-19_{0,19}$ & $45993.369 \pm 0.02$ & & & & $\mathrm{H}$ \\
\hline
\end{tabular}




\section{Appendix $\mathrm{B}$ : The isomers of $c-\mathrm{C}_{3} \mathrm{HCCH}$}

The isomeric family with formula $\mathrm{H}_{2} \mathrm{C}_{5}$ is composed of five molecular species. The non-polar pentadiynylidene $(\mathrm{HCCCCH})$ and ethynyl cyclopropenylidene $\left(c-\mathrm{C}_{3} \mathrm{HCCH}\right)$ are the most stable isomers, and their energy separation is very small, $\sim 0.043 \mathrm{eV}$. $\mathrm{H}_{2} \mathrm{CCCCC}$ is a high energy isomer that lies $0.564 \mathrm{eV}$ above the ground. Another two species, $\mathrm{HCC}(\mathrm{CH}) \mathrm{CC}$ and $c-\mathrm{C}_{3} \mathrm{H}_{2} \mathrm{CC}$, are part of this isomeric family and are located at 0.737 and $0.910 \mathrm{eV}$, respectively, above the most stable forms (Seburg et al. 1997).

The rotational transitions in the $31-50 \mathrm{GHz}$ of $\mathrm{HCC}(\mathrm{CH}) \mathrm{CC}$, one of the $\mathrm{C}_{5} \mathrm{H}_{2}$ isomers, can be predicted with high accuracy from the laboratory data of Gottlieb et al. (1998). We obtain a $3 \sigma$ upper limit to its column density of $2 \times 10^{10} \mathrm{~cm}^{-2}$. It should be noted that the dipole moment of this species is $4.52 \mathrm{D}$ (Gottlieb et al. 1998). An even larger dipole moment was calculated by the same authors for the isomer $c-\mathrm{C}_{3} \mathrm{H}_{2} \mathrm{CC}(8.2 \mathrm{D})$. For this species we derive a $3 \sigma$ upper limit to its column density of $9 \times 10^{9} \mathrm{~cm}^{-2}$. Finally, the cumulenic species $\mathrm{H}_{2} \mathrm{C}_{5}$ was recently detected from our data, and the results will be published elsewhere (Cabezas et al., in prep.).

An additional derivate of $c-\mathrm{C}_{3} \mathrm{H}_{2}$ is cyano propenylidene $\left(c-\mathrm{C}_{3} \mathrm{HCN}\right)$, which was observed in the laboratory by McCarthy et al. (1999). We searched for it in our data and derive a $3 \sigma$ upper limit to its column density of $2.5 \times 10^{11} \mathrm{~cm}^{-2}$.

\section{Appendix C: Improved rotational constants for $c-\mathrm{C}_{3} \mathrm{HCCH}$ and $c-\mathrm{C}_{9} \mathrm{H}_{8}$}

Table C.1. Rotational and distortion constants of $c-\mathrm{C}_{3} \mathrm{HCCH}$.

\begin{tabular}{lcc}
\hline \hline Constant & Laboratory $^{(a)}$ & This work \\
\hline$A(\mathrm{MHz})$ & $34638.7012(27)$ & $34638.7023(26)$ \\
$B(\mathrm{MHz})$ & $3424.87685(43)$ & $3424.87678(42)$ \\
$C(\mathrm{MHz})$ & $3113.63856(50)$ & $3113.63900(44)$ \\
$\Delta_{J}(\mathrm{kHz})$ & $0.2877(80)$ & $0.2918(74)$ \\
$\Delta_{J K}(\mathrm{kHz})$ & $29.53(24)$ & $29.72(21)$ \\
\hline Number of lines & 13 & 26 \\
$\sigma(\mathrm{kHz})$ & 2.1 & 26 \\
$J_{\max }, K_{\max }$ & 7,1 & 10,1 \\
$v_{\max }(\mathrm{GHz})$ & 26.130 & 43.979 \\
\hline
\end{tabular}

Notes. Values between parentheses correspond to the uncertainties of the parameters in units of the least significant digits. ${ }^{(a)}$ Laboratory frequencies from Travers et al. (1997).

The frequencies we have measured in TMC-1 can be used to improve the rotational and distortion constants of $c-\mathrm{C}_{3} \mathrm{HCCH}$ and indene. We used the fitting code FITWAT described in Cernicharo et al. (2018).

Table C. 1 provides the results obtained by fitting the laboratory data of Travers et al. (1997) for $c-\mathrm{C}_{3} \mathrm{HCCH}$ alone, as well as those obtained from a fit to the merged laboratory plus the TMC-1 frequencies. An improvement of the uncertainty in the rotational and distortion constants was obtained. The fit to the laboratory data alone results in exactly the same constants as those obtained by Travers et al. (1997).

Table C. 2 provides the same information but for indene. The 50 lines measured in TMC-1 (three of them are unresolved doublets) provide a significant improvement of the rotational and distortion constants for this species.
Table C.2. Rotational and distortion constants of $c-\mathrm{C}_{9} \mathrm{H}_{8}$.

\begin{tabular}{lcc}
\hline \hline Constant & Laboratory ${ }^{(a)}$ & This work \\
\hline$A(\mathrm{MHz})$ & $3775.048(15)$ & $3775.0469(80)$ \\
$B(\mathrm{MHz})$ & $1580.8656(21)$ & $1580.86511(79)$ \\
$C(\mathrm{MHz})$ & $1122.2460(18)$ & $1122.24773(51)$ \\
$\Delta_{J}(\mathrm{kHz})$ & $0.0326(38)$ & $0.03349(97)$ \\
$\Delta_{J K}(\mathrm{kHz})$ & $0.050(11)$ & $0.0517(73)$ \\
$\Delta_{K}(\mathrm{kHz})$ & $0.37(12)$ & $0.329(82)$ \\
$\delta_{J}(\mathrm{kHz})$ & $0.0117(12)$ & $0.01068(51)$ \\
$\delta_{K}(\mathrm{kHz})$ & $0.068(19)$ & $0.0775(94)$ \\
\hline Number of lines & 78 & 128 \\
$\sigma(\mathrm{kHz})$ & 67 & 54 \\
$J_{\max }, K_{\max }$ & 30,13 & 30,13 \\
$\nu_{\max }(\mathrm{GHz})$ & 39.3 & 45.99 \\
\hline
\end{tabular}

Notes. Values between parentheses correspond to the uncertainties of the parameters in units of the least significant digits. ${ }^{(a)}$ Laboratory frequencies from Li et al. (1979) and Caminati (1993).

The merged fits are recommended for predicting the frequency of the rotational transitions of both species with uncertainties between 10 and $200 \mathrm{kHz}$ up to $115 \mathrm{GHz}$.

\section{Appendix D: Column density of $c-\mathrm{C}_{3} \mathrm{H}_{2}$}

The polar carbene ring molecule $c-\mathrm{C}_{3} \mathrm{H}_{2}$ is widespread in interstellar and circumstellar clouds (Matthews \& Irvine 1985). For the physical conditions of TMC-1, we expect only a few lines of this molecule to be strong enough within the frequency coverage of our survey. In fact, only one ortho line, the $3_{21}-3_{12}$ at $44104.777 \mathrm{MHz}$, has an upper energy level below $20 \mathrm{~K}$. This line appears in our data in absorption, as shown in Fig. D.1. We verified that the absorption is real and not produced by a negative feature created during the folding of the frequency switching data by analysing separately the two frequency throws used during the observations. This line was predicted to be in absorption by Avery \& Green (1989) for the typical densities of cold dark clouds, but to the best of our knowledge it had not been reported before now. The other two lines of the ortho species in our survey have upper level energies around $45 \mathrm{~K}$ and are not detected. Absorption from $c-\mathrm{C}_{3} \mathrm{H}_{2}$ in cold dark clouds has previously been reported for its para line $220-211$ at $21.6 \mathrm{GHz}$ (Matthews et al. 1986). For the para species, three lines are detected in our data, as shown in Fig. D.1. They are the $4_{40}-4_{31}$ at $35.36 \mathrm{GHz}$, the $4_{31}-4_{22}$ at $42.231 \mathrm{GHz}$, and the $2_{11}-2_{02}$ at $46.755 \mathrm{GHz}$. The first one also appears in absorption. We verified, as for $3_{21}-3_{12}$ ortho transition, that the absorption is real. The other two para lines are in emission.

Collisional rates between $c-\mathrm{C}_{3} \mathrm{H}_{2}$ and $\mathrm{He}$ adapted to the low temperatures of cold dark clouds are available from Avery \& Green (1989) and Khalifa et al. (2019). We performed large velocity gradient (LVG) calculations for ortho and para cyclopropenylidene species by varying the density and the column density and by adopting the most recent set of collisional rates. The radius of the source is fixed to 40" (Fossé et al. 2001) and the line width to $0.5 \mathrm{~km} \mathrm{~s}^{-1}$. The best fit to the three observed para lines is obtained for $n\left(\mathrm{H}_{2}\right)=(4.0 \pm 0.5) \times 10^{4} \mathrm{~cm}^{-2}$ and $N\left(p-\mathrm{C}_{3} \mathrm{H}_{2}\right)=(1.4 \pm 0.3) \times 10^{13} \mathrm{~cm}^{-2}$. By adopting the derived density for the para species, the ortho absorption line can then be reproduced for a column density of $N\left(o-\mathrm{C}_{3} \mathrm{H}_{2}\right)=$ $4.5 \times 10^{13} \mathrm{~cm}^{-2}$. Hence, the ortho to para abundance ratio of $c-\mathrm{C}_{3} \mathrm{H}_{2}$ is $\sim 3$, which is the value expected from the spin degen- 

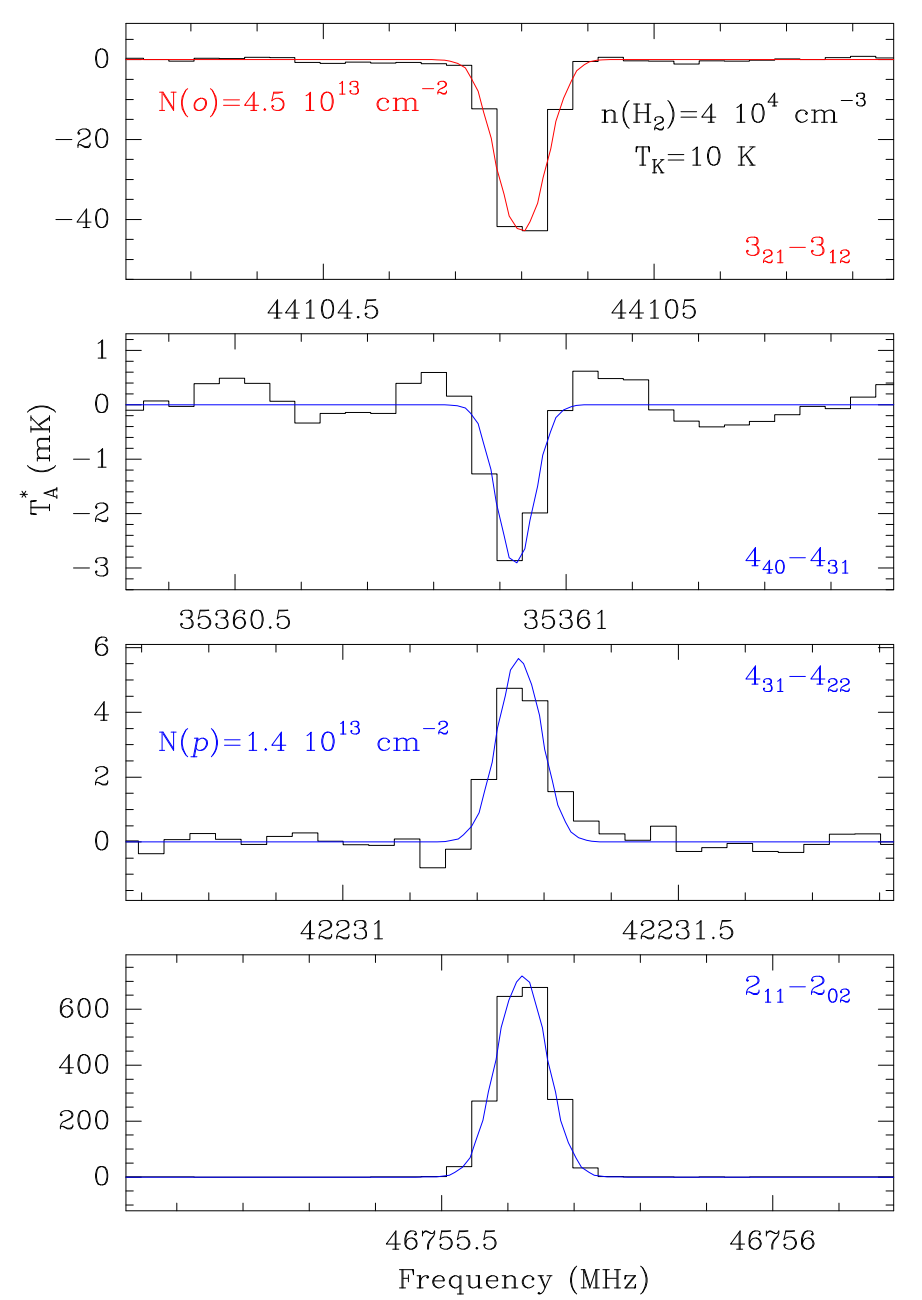

Fig. D.1. Observed transitions of $c-\mathrm{C}_{3} \mathrm{H}_{2}$ in TMC-1. The abscissa corresponds to the rest frequency of the lines, assuming a local standard of rest velocity of the source of $5.77 \mathrm{~km} \mathrm{~s}^{-1}$. The ordinate is the antenna temperature, corrected for atmospheric and telescope losses, in millikelvins. The quantum numbers for each transition are indicated in the upper or lower right corner of the corresponding panel. The red line shows the computed synthetic spectrum for this species (see text). Blue labels indicate the multiplicative factor applied, when needed, to the model to match the intensity of the observed lines.

eracy of the two species. The total column density of cyclopropenylidene is $5.9 \times 10^{13} \mathrm{~cm}^{-2}$, in very good agreement with the value derived by Fossé et al. (2001) of $5.8 \times 10^{13} \mathrm{~cm}^{-2}$. Nevertheless, the derived abundances rely on the accuracy of the collisional rate coefficients. The synthetic spectrum computed from these parameters is shown by the red (ortho) and blue (para) lines in Fig. D.1, and it reproduces nicely the ortho and para absorption lines as well as the two para emission lines. If we use the collisional rates calculated by Avery \& Green (1989), a reasonable fit can be obtained by reproducing the two absorption lines. In this case, the derived volume density is $n\left(\mathrm{H}_{2}\right)=(2.8 \pm 0.5) \times 10^{4} \mathrm{~cm}^{-3}$ and the best fits to the intensities correspond to $N\left(o-\mathrm{C}_{3} \mathrm{H}_{2}\right)=(2.8 \pm 0.5) \times 10^{13} \mathrm{~cm}^{-2}$ and $N\left(p-\mathrm{C}_{3} \mathrm{H}_{2}\right)=(3.2 \pm 0.5) \times 10^{13} \mathrm{~cm}^{-2}$. With these less accurate collisional rates, the ortho/para ratio is $\sim 1$. Moreover, deviations of up to $20 \%$ between calculated and observed intensities are observed for the best model fit. These deviations are not observed when we use the most recent calculations of Khalifa et al. (2019), which are based on a more precise determination of the potential energy surface of the $c-\mathrm{C}_{3} \mathrm{H}_{2} / \mathrm{He}$ system. For both sets of rates, the derived total column density of $c-\mathrm{C}_{3} \mathrm{H}_{2}$ is practically identical, $\sim 6 \times 10^{13} \mathrm{~cm}^{-2}$. In view of the complex system of absorption and emission lines shown by this molecular species, collisional rates using $\mathrm{H}_{2}$ as a collider are highly desirable.

\section{Appendix E: Column density of $c-\mathrm{C}_{3} \mathrm{H}$}

Cyclopropanediylidenyl $\left(c-\mathrm{C}_{3} \mathrm{H}\right)$ has been detected towards several astrophysical environments, including cold dark clouds, evolved stars, and translucent molecular clouds (Yamamoto et al. 1987; Mangum \& Wooten 1990; Turner et al. 2000; Cernicharo et al. 2000). Several lines pertaining to the fine and hyperfine structure of the $2_{1,1}-2_{1,2}$ rotational transitions of this species are within our line survey of TMC-1. The data for all the strongest components, and some of the weak ones, are shown in Fig. E.1. Several of the panels of this figure show a significant number of unknown features. This is an important drawback for any stacking procedure used to detect molecules producing intensities below $1 \mathrm{mK}$ for their rotational transitions. At this level of sensitivity, TMC-1 cannot be considered as a line-poor source, and detections have to be performed using the standard procedure of line-by-line detection.

With only one transition, we have to assume a rotational temperature in order to derive a column density for the molecule. The energy of the upper level of the different fine and hyperfine components of the $2_{1,1}-2_{1,2}$ transition is $\sim 6.5 \mathrm{~K}$. Hence, the column density will depend slightly on the adopted value of $T_{\mathrm{r}}$ (see e.g. the error analysis carried out by Cernicharo et al. 2021c for $\mathrm{HC}_{3} \mathrm{~S}^{+}$). Assuming $T_{\mathrm{r}}=10 \mathrm{~K}$, a source diameter of $80^{\prime \prime}$, and a line width of $0.6 \mathrm{~km} \mathrm{~s}^{-1}$, we obtain a column density for $c-\mathrm{C}_{3} \mathrm{H}$ of $(1.2 \pm 0.2) \times 10^{12} \mathrm{~cm}^{-2}$. This value is a factor of five smaller than the one derived by Yamamoto et al. (1987), who observed the $2_{1,2}-1_{1,1}$ transition at $\sim 91.5 \mathrm{GHz}$ with the Nobeyama radio telescope. They assumed a rotational temperature of $5 \mathrm{~K}$. In order to understand this large difference, we used the data gathered with the IRAM 30m telescope during the $3 \mathrm{~mm}$ line survey of TMC-1 (Marcelino et al. 2007). We obtain intensities for the $2_{1,2}-1_{1,1}$ hyperfine components that are similar to those of Yamamoto et al. (1987). The $3 \mathrm{~mm}$ data are shown in Fig. E.2. Assuming an identical rotational temperature for the two transitions, it is not possible to get a reliable fit to the observed intensities. In fact, the $3 \mathrm{~mm}$ lines are well explained with a column density of $(6.2 \pm 0.4) \times 10^{12} \mathrm{~cm}^{-2}$ for $T_{\mathrm{r}}=5 \mathrm{~K}$, a very similar value to that of Yamamoto et al. (1987). However, the rotational temperature has to be decreased to $3.7 \mathrm{~K}$ to explain with the same column density the observed intensities for the $2_{1,1}-2_{1,2}$. The two transitions share the same lower level (the fundamental one), but they could have significantly different excitation temperatures if the collisional rates from the ground to the two upper levels are different. Unfortunately, no collisional rates for $c-\mathrm{C}_{3} \mathrm{H}$ are available in the literature. 
J. Cernicharo et al.: Hydrocarbon cycles in TMC-1
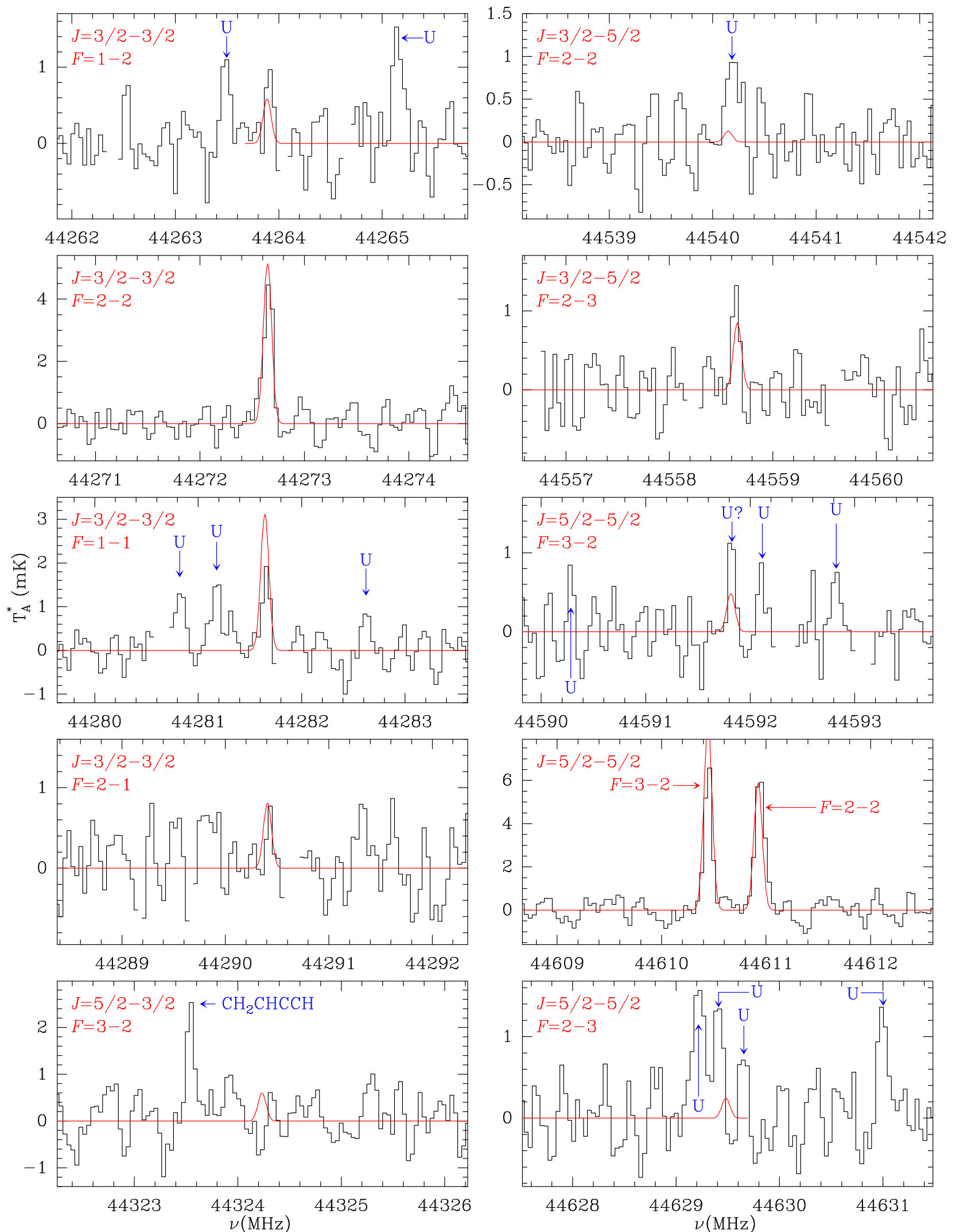

Fig. E.1. Fine and hyperfine components of the $2_{1,1}-1_{1,1}$ transition of $c-\mathrm{C}_{3} \mathrm{H}$ in TMC-1 as observed with the Yebes $40 \mathrm{~m}$ radio telescope. The abscissa corresponds to the rest frequency of the lines, assuming a local standard of rest velocity of the source of $5.83 \mathrm{~km} \mathrm{~s}^{-1}$. The ordinate is the antenna temperature, corrected for atmospheric and telescope losses, in millikelvins. The quantum numbers for each transition are indicated in the upper or lower right corner of the corresponding panel. The red line shows the computed synthetic spectrum for this species for a column density of $6.2 \times 10^{12} \mathrm{~cm}^{-2}$ and $T_{\mathrm{r}}=3.7 \mathrm{~K}$ (see text). 

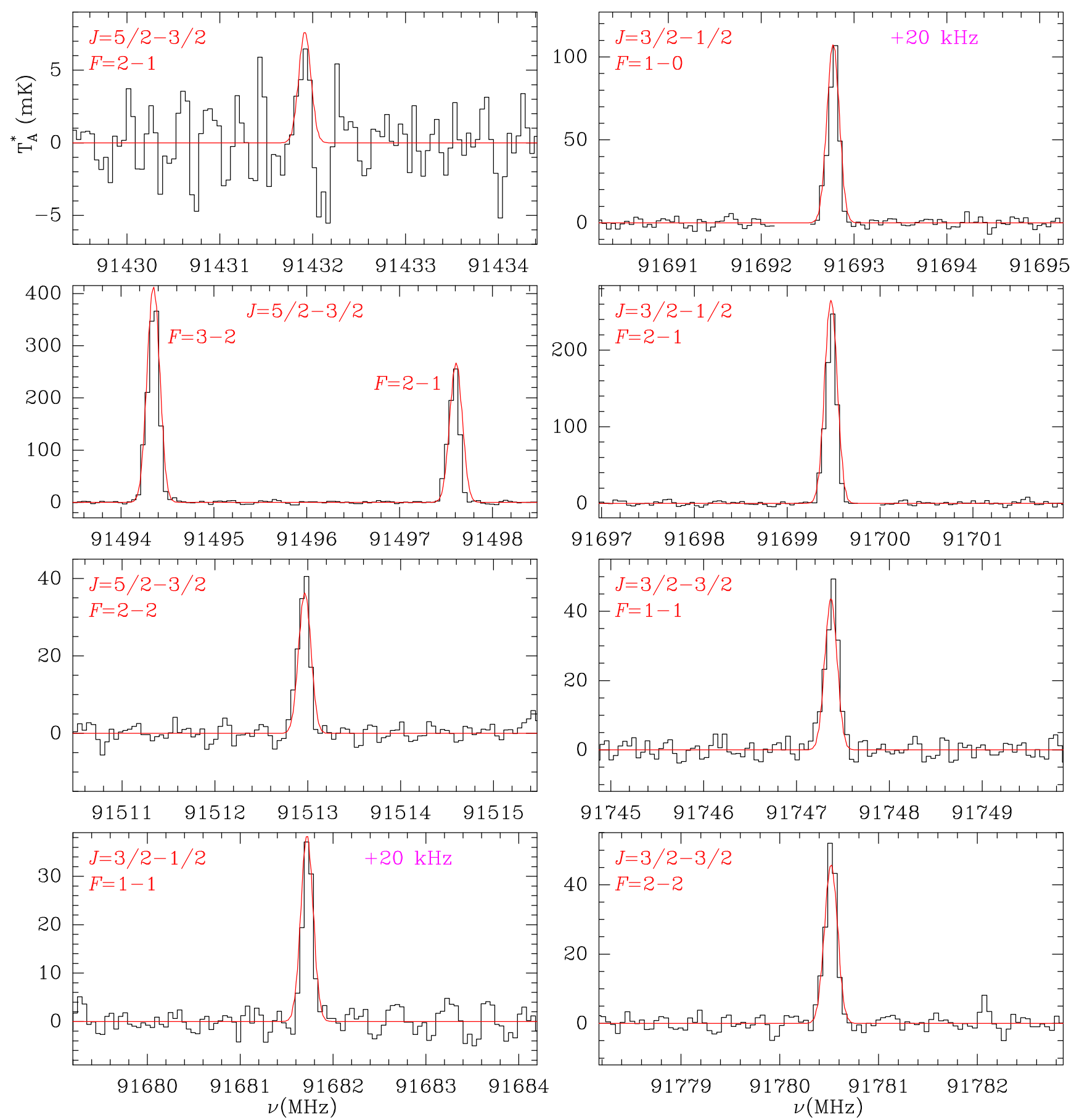

Fig. E.2. Fine and hyperfine components of the $2_{1,2}-1_{1,1}$ transition of $c$ - $\mathrm{C}_{3} \mathrm{H}$ in TMC-1 as observed with the IRAM $30 \mathrm{~m}$ radio telescope (data from Marcelino et al. 2007). The abscissa corresponds to the rest frequency of the lines, assuming a local standard of rest velocity of the source of $5.83 \mathrm{~km} \mathrm{~s}^{-1}$. The ordinate is the antenna temperature, corrected for atmospheric and telescope losses, in millikelvins. The quantum numbers for each transition are indicated in the upper or lower right corner of the corresponding panel. The red line shows the computed synthetic spectrum for this species for a column density of $6.2 \times 10^{12} \mathrm{~cm}^{-2}$ and $T_{\mathrm{r}}=5 \mathrm{~K}$ (see text). Violet labels indicate the observed-minus-calculated frequencies when larger than $5 \mathrm{kHz}$. 